\title{
Mechanisms of Action of Antiseizure Drugs and the Ketogenic Diet
}

\author{
Michael A. Rogawski ${ }^{1}$, Wolfgang Löscher ${ }^{2}$, and Jong M. Rho ${ }^{3,4,5}$ \\ ${ }^{1}$ Department of Neurology, University of California, Davis, Sacramento, California 95817 \\ ${ }^{2}$ Department of Pharmacology, Toxicology, and Pharmacy, University of Veterinary Medicine, \\ Hannover, Germany \\ ${ }^{3}$ Department of Pediatrics, University of Calgary, Calgary, Alberta, Canada \\ ${ }^{4}$ Department of Clinical Neurosciences, University of Calgary, Calgary, Alberta, Canada \\ ${ }^{5}$ Department of Physiology and Pharmacology, University of Calgary, Alberta, Canada \\ Correspondence: rogawski@ucdavis.edu; wolfgang.loescher@tiho-hannover.de; jong.rho@albertahealthservices.ca
}

\begin{abstract}
Antiseizure drugs (ASDs), also termed antiepileptic drugs, are the main form of symptomatic treatment for people with epilepsy, but not all patients become free of seizures. The ketogenic diet is one treatment option for drug-resistant patients. Both types of therapy exert their clinical effects through interactions with one or more of a diverse set of molecular targets in the brain. ASDs act by modulation of voltage-gated ion channels, including sodium, calcium, and potassium channels; by enhancement of $\gamma$-aminobutyric acid (GABA)-mediated inhibition through effects on $\mathrm{GABA}_{\mathrm{A}}$ receptors, the GABA transporter 1 (GAT1) GABA uptake transporter, or GABA transaminase; through interactions with elements of the synaptic release machinery, including synaptic vesicle $2 \mathrm{~A}(\mathrm{SV} 2 \mathrm{~A})$ and $\alpha 2 \delta$; or by blockade of ionotropic glutamate receptors, including $\alpha$-amino-3-hydroxy-5-methyl-4-isoxazole-propionate (AMPA) receptors. The ketogenic diet leads to increases in circulating ketones, which may contribute to the efficacy in treating pharmacoresistant seizures. Production in the brain of inhibitory mediators, such as adenosine, or ion channel modulators, such as polyunsaturated fatty acids, may also play a role. Metabolic effects, including diversion from glycolysis, are a further postulated mechanism. For some ASDs and the ketogenic diet, effects on multiple targets may contribute to activity. Better understanding of the ketogenic diet will inform the development of improved drug therapies to treat refractory seizures.
\end{abstract}

\begin{abstract}
$A^{\text {ntiseizure drugs (ASDs), often referred to as }}$ Aantiepileptic drugs or anticonvulsant drugs, are administered chronically with the intent of preventing the occurrence of epileptic seizures in a person at risk. Although limited results from animal studies or uncontrolled clinical studies suggest that some ASDs might have antiepileptogenic actions (Kaminski et al. 2014),
\end{abstract}

there is insufficient evidence to conclude that any ASD can produce clinically useful disease modification. The symptomatic relief from seizures that ASDs provide occurs through interactions with a variety of cellular targets. The actions on these targets can be categorized into four broad groups: (1) modulation of voltage-gated ion channels, including sodium, cal-

Editors: Gregory L. Holmes and Jeffrey L. Noebels

Additional Perspectives on Epilepsy: The Biology of a Spectrum Disorder available at www.perspectivesinmedicine.org

Copyright (C) 2016 Cold Spring Harbor Laboratory Press; all rights reserved; doi: 10.1101/cshperspect.a022780

Cite this article as Cold Spring Harb Perspect Med 2016;6:a022780 
M.A. Rogawski et al.

Table 1. Molecular targets of clinically used ASDs

\begin{tabular}{|c|c|}
\hline Molecular target & ASDs that act on target \\
\hline \multicolumn{2}{|l|}{ Voltage-gated ion channels } \\
\hline Voltage-gated sodium channels & $\begin{array}{l}\text { Phenytoin, fosphenytoin, }{ }^{\mathrm{a}} \text { carbamazepine, oxcarbazepine, }{ }^{\mathrm{b}} \\
\text { eslicarbazepine acetate, }{ }^{\mathrm{c}} \text { lamotrigine, lacosamide; possibly } \\
\text { topiramate, zonisamide, rufinamide }\end{array}$ \\
\hline Voltage-gated calcium channels (T-type) & Ethosuximide \\
\hline Voltage-gated potassium channels $\left(\mathrm{K}_{\mathrm{v}} 7\right)$ & Ezogabine \\
\hline \multicolumn{2}{|l|}{ GABA inhibition } \\
\hline $\mathrm{GABA}_{\mathrm{A}}$ receptors & $\begin{array}{l}\text { Phenobarbital, primidone, benzodiazepines, including } \\
\text { diazepam, lorazepam, and clonazepam; possibly } \\
\text { topiramate, felbamate, ezogabine }\end{array}$ \\
\hline GAT1 GABA transporter & Tiagabine \\
\hline GABA transaminase & Vigabatrin \\
\hline \multicolumn{2}{|l|}{ Synaptic release machinery } \\
\hline SV2A & Levetiracetam \\
\hline$\alpha 2 \delta$ & Gabapentin, gabapentin enacarbil, ${ }^{\mathrm{d}}$ pregabalin \\
\hline \multicolumn{2}{|l|}{ Ionotropic glutamate receptors } \\
\hline AMPA receptor & Perampanel \\
\hline Mixed/unknown & $\begin{array}{l}\text { Valproate, felbamate, topiramate, zonisamide, rufinamide, } \\
\text { adrenocorticotrophin }\end{array}$ \\
\hline $\begin{array}{l}\text { From Rogawski and Cavazos 2015; adapted, wi } \\
\text { GABA, } \gamma \text {-Aminobutyric acid; GAT1, } \gamma \text {-amin } \\
\alpha \text {-amino-3-hydroxy-5-methyl-4-isoxazole-propio } \\
{ }^{\mathrm{a}} \text { Fosphenytoin is a prodrug for phenytoin. } \\
{ }^{\mathrm{b}} \text { Oxcarbazepine serves largely as a prodrug for } \\
{ }^{\mathrm{c}} \text { Eslicarbarbazepine acetate is a prodrug for } S \text { - } \\
{ }^{\mathrm{d}} \text { Gabapentin enacarbil is a prodrug for gabape }\end{array}$ & $\begin{array}{l}\text { yric acid transporter 1; SV2A, synaptic vesicle protein 2A; AMPA, } \\
\text { rbazepine, mainly S-licarbazepine. } \\
\text { bazepine. }\end{array}$ \\
\hline
\end{tabular}

cium, and potassium channels; (2) enhancement of $\gamma$-aminobutyric acid (GABA) inhibition through effects on $\mathrm{GABA}_{\mathrm{A}}$ receptors, the GAT1 GABA transporter or GABA transaminase; (3) direct modulation of synaptic release through effects on components of the release machinery, including synaptic vesicle protein $2 \mathrm{~A}$ (SV2A) and the $\alpha 2 \delta$ subunit of voltagegated calcium channels; and (4) inhibition of synaptic excitation mediated by ionotropic glutamate receptors, including $\alpha$-amino-3-hydroxy5-methyl-4-isoxazole-propionate (AMPA) receptors (Table 1). The result of the interactions at these diverse targets is to modify the intrinsic excitability properties of neurons or to alter fast inhibitory or excitatory neurotransmission. These actions reduce the probability of seizure occurrence by modifying the bursting properties of neurons (reducing the capacity of neurons to fire action potentials at high rate) and reducing synchronization in localized neuronal ensembles. In addition, ASDs inhibit the spread of abnormal firing to adjacent and distant brain sites. This occurs through strengthening of the inhibitory surround, a function predominantly of GABA released from interneurons acting on $\mathrm{GABA}_{\mathrm{A}}$ receptors, and by inhibition of glutamate-mediated excitatory neurotransmission within the network of principal (relay) neurons. Some seizures, including typical generalized absence seizures, result from elevated thalamocortical synchronization. ASDs effective against these seizure types interfere with the rhythmgenerating mechanisms that underlie synchronized activity in the thalamocortical circuitry. In this review, we consider each of the principal targets of ASDs and discuss how, to the extent known, these agents affect the activity of these targets. The goal of epilepsy therapy is the complete elimination of seizures. This objective is not achievable for many patients. When ASDs are not able to control seizures, some patients 
may benefit from dietary therapies. The ketogenic diet is the most widely used and best validated such treatment approach. Here, we review a variety of theories to explain the action of the ketogenic diet in the treatment of epilepsy ranging from the view that the antiseizure activity relates to ketone bodies or the production of inhibitory mediators, such as adenosine, to the hypothesis that it is a result of shifts in intermediary metabolism.

\section{VOLTAGE-GATED ION CHANNELS}

\section{Voltage-Gated Sodium Channels}

Voltage-gated sodium channels play an essential role in the initiation and propagation of action potentials in neurons (Mantegazza et al. 2010). Neuronal depolarizations by only a few millivolts, which ordinarily result from activation of synaptic glutamate receptors (mainly AMPA receptors, but also $N$-methyl-D-aspartate [NMDA] receptors), cause sodium channels to open and enable influx of sodium along its electrochemical gradient. These channels then inactivate within milliseconds. The influx of sodium ions during the brief time that sodium channels are open generates the depolarizing component (upstroke) of the action potential. Although nearly all sodium channels inactivate on depolarization, $\sim 1 \%$ of the sodium current is noninactivating, resulting in a small persistent sodium current $\left(\mathrm{I}_{\mathrm{NaP}}\right)$, which is carried by the same channels as the fast transient current. $\mathrm{I}_{\mathrm{NaP}}$ facilitates epileptic burst firing by reducing the threshold for action potential generation, sustained repetitive firing, and augmentation of depolarizing synaptic currents (Stafstrom 2007). Some ASDs, most notably phenytoin, inhibit $\mathrm{I}_{\mathrm{NaP}}$, an action that is believed to contribute to their efficacy (Mantegazza et al. 2010).

Voltage-gated sodium channels are multimeric protein complexes, composed of a large $\alpha$-subunit that forms four subunit-like homologous domains (designated I-IV) and one or more smaller $\beta$ subunits (Meldrum and Rogawski 2007). The ion-conducting pore is contained within the $\alpha$-subunit, as are the elements of the channel that mediate its fundamental physio- logical properties, including rapid inactivation. The $\alpha$ subunits alone are able to form a functional sodium channel, but $\beta$ subunits ( $\beta 1-\beta 4$ are known) can modulate the kinetics and trafficking of the channel (Patino and Isom 2010). Of the 10 known $\alpha$ subunits, using the channel and receptor nomenclature of Alexander et al. (2013), $\mathrm{Na}_{\mathrm{v}} 1.1, \mathrm{Na}_{\mathrm{v}} 1.2, \mathrm{Na}_{\mathrm{v}} 1.3$, and $\mathrm{Na}_{\mathrm{v}} 1.6$ are the four most abundantly expressed subunits in the brain (Yu and Catterall 2003; Vacher et al. 2008). Mutations in voltage-gated sodium channels have been associated with various genetic forms of epilepsy (Oliva et al. 2012).

ASDs that protect against seizures through an interaction with voltage-gated sodium channels are commonly referred to as "sodium channel blockers" (Fig. 1). They are among the most frequently used drugs in the treatment of both focal and primary generalized tonic-clonic seizures. Such drugs include phenytoin, carbamazepine, lamotrigine, oxcarbazepine (as well as its active metabolite licarbazepine), rufinamide, and lacosamide. ASDs that interact with voltage-gated sodium channels also show a characteristic "use-dependent" blocking action so that they inhibit high-frequency trains of action potentials much more potently than they attenuate individual action potentials or firing at low frequencies. Because they also show a "voltage-dependence" to their blocking action, sodium-channel-blocking ASDs are more potent at inhibiting action potentials superimposed on a depolarized plateau potential as characteristically occurs with seizures. Thus, importantly, sodium-channel-blocking ASDs preferentially inhibit seizure discharges in relation to normal ongoing neural activity. By virtue of their ability to inhibit the action potential invasion of nerve terminals, sodium-channelblocking ASDs inhibit the release of diverse neurotransmitters, including glutamate; whether this is responsible for the therapeutic activity of the drugs remains uncertain (Waldmeier et al. 1995).

The binding site for sodium on sodiumchannel-blocking ASDs is believed to overlap with the binding site of local anesthetics, which is within the pore of the channel and is formed by the S6 segments of domains I, II, and IV. 
M.A. Rogawski et al.

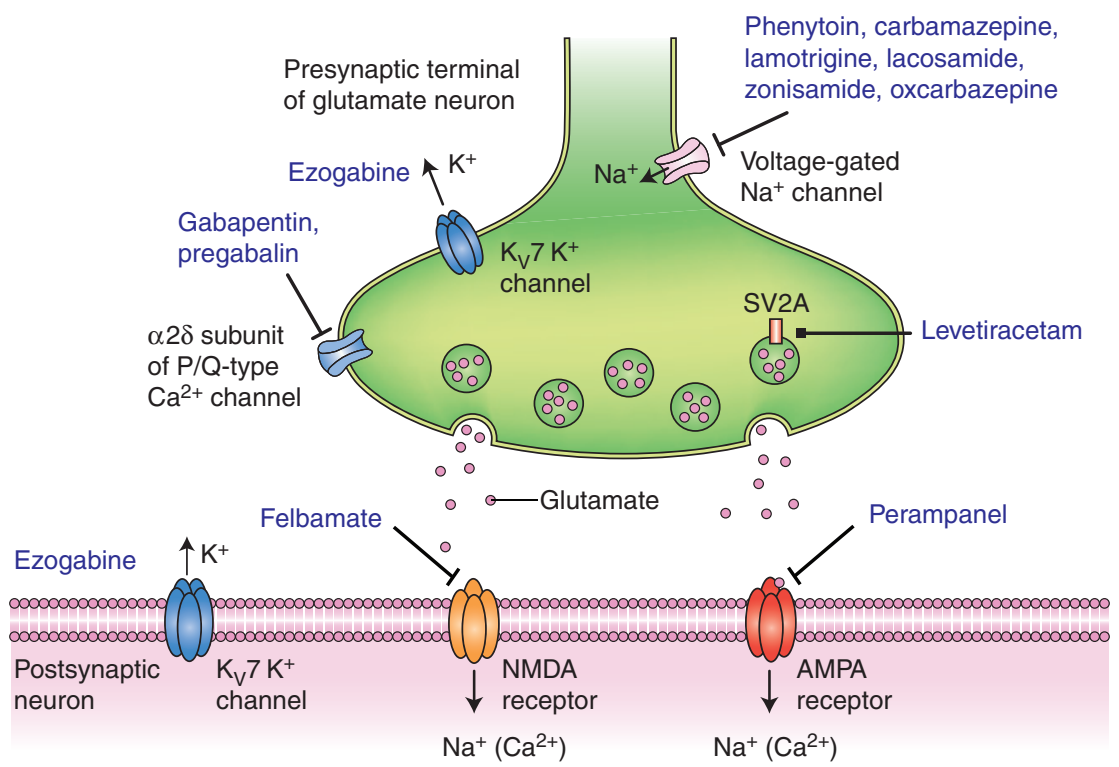

Figure 1. Diverse molecular targets for antiseizure drugs (ASDs) at excitatory glutamatergic synapses. Seizure protection can be conferred by effects on voltage-gated sodium channels, M-type voltage-gated potassium channels $\left(\mathrm{K}_{\mathrm{v}} 7\right)$, and voltage-gated calcium channels located in presynaptic terminals. Additional presynaptic targets include the synaptic vesicle protein SV2A and the $\alpha 2 \delta$ accessory subunit of voltage-gated calcium channels. These presynaptic targets may act to diminish glutamate release. Postsynaptic targets include ionotropic glutamate receptors of the $N$-methyl-D-aspartate (NMDA) and $\alpha$-amino-3-hydroxy-5-methyl-4-isoxazole-propionate (AMPA) types.

Sodium-channel-blocking ASDs bind with higher affinity to this site when the channel is in the inactivated state, and, when such a drug is bound, the channel is stabilized in the inactivated state (Mantegazza et al. 2010). When neurons are depolarized and firing rapidly, sodium channels spend a greater amount time in the inactivated state and are able to accumulate bound drug so that they become trapped in the inactivated state. This accounts for the useand voltage-dependent blocking action that they show. Phenytoin, carbamazepine, and lamotrigine are considered "classical" sodiumchannel-blocking ASDs. Lacosamide is also believed to induce its therapeutic effects by interacting with sodium channels (Rogawski et al. 2015). However, unlike other sodium-channelblocking ASDs, lacosamide does not inhibit high-frequency repetitive spike firing on the time scale of hundreds of milliseconds. It does, however, inhibit spike firing in long trains of spikes on the time scale of $1-2 \mathrm{sec}$. It has been proposed that the very slow action of lacosamide is caused by an enhancement of a distinct and poorly understood form of inactivation, referred to as "slow inactivation." An alternative explanation is that lacosamide binds more slowly to fast-inactivated sodium channels than do the other sodium-channel-blocking ASDs. In any case, the unusually slow development of block produced by lacosamide during highfrequency activity could allow lacosamide to better discriminate between seizure-like pathological firing and normal network activity.

\section{T-Type Voltage-Gated Calcium Channels}

Low-voltage-activated (T-type) calcium channels play a major role in the intrinsic thalamocortical oscillations that underlie the spike-wave discharges of generalized absence seizures (Avoli et al. 2001; Huguenard 2002; Lambert et al. 2014). There are three $\mathrm{T}$-type $\mathrm{Ca}^{2+}$ channel isoforms encoded by separate genes, denoted as 
$\mathrm{Ca}_{\mathrm{v}} 3.1(\alpha 1 \mathrm{G}), \mathrm{Ca}_{\mathrm{v}} 3.2(\alpha 1 \mathrm{H})$, and $\mathrm{Ca}_{\mathrm{v}} 3.3(\alpha 1 \mathrm{I})$ All three T-type calcium channel isoforms are expressed in thalamocortical circuits (Talley et al. 1999). $\mathrm{Ca}_{\mathrm{v}} 3.1$ is prominently expressed in thalamic relay neurons in the dorsal thalamus, which plays a key role in absence seizures; $\mathrm{Ca}_{\mathrm{v}} 3.2$ - and to a lesser extent $\mathrm{Ca}_{\mathrm{v}} 3.3$-are prominently expressed in thalamic reticular neurons. All three T-type calcium channel isoforms are expressed in the cortex, with $\mathrm{Ca}_{\mathrm{v}} 3.2$ mainly localized to layer V. In non-REM sleep, including when $\delta$ waves, sleep spindles, and $\mathrm{K}$-complexes occur, the thalamocortical circuit switches from a tonic to oscillatory mode of firing, but in absence epilepsy, this switching can occur inappropriately, even during wakefulness (Crunelli et al. 2014; Powell et al. 2014). T-type calcium channels in the thalamus and cortex contribute to the abnormal behavior of the circuit. These channels generate lowthreshold spikes, leading to burst firing and oscillatory behavior (Suzuki and Rogawski 1989). GABAergic neurons of the thalamic reticular nucleus are also critically involved in absence seizures as they hyperpolarize thalamic relay neurons, which de-inactivate T-type calcium channels, allowing the channels to generate burst firing and the propagation of spike-wave discharges in the thalamocortical circuit ( $\mathrm{Da}$ nober et al. 1998).

Ethosuximide, which is highly efficacious in the treatment of absence seizures-but not other seizure types - is thought to act by inhibition of T-type calcium channels in the thalamocortical circuit (Coulter et al. 1989; Broicher et al. 2007; Gören and Onat 2007). At clinically relevant concentrations $(20-40 \mu \mathrm{g} / \mathrm{ml})$, some but not all investigators have observed a partial $(20 \%-30 \%)$ reduction of T-type calcium current by ethosuximide. Notwithstanding this discrepancy, studies with recombinant T-type calcium channels have confirmed that ethosuximide blocks all three channel types (Gomora et al. 2001). The block increases when the current is activated from more depolarized potentials and when T-type calcium channels are inactivated, as occurs especially during highfrequency activation, so that the drug has selectivity for pathological behavior in the tha- lamocortical circuit, which is associated with neuronal depolarization and inactivation of T-type calcium channels. Effects on other membrane currents, including $\mathrm{I}_{\mathrm{NaP}}$, calcium-activated potassium current (Broicher et al. 2007), and inward rectifier potassium current (Huang and Kuo 2015), may contribute to the efficacy of ethosuximide in absence epilepsy. Remarkably, results in animal models indicate that early treatment with ethosuximide can have diseasemodifying (i.e., antiepileptogenic) effects, causing a persistent reduction in seizures and mitigation of behavioral comorbidities (Blumenfeld et al. 2008; Dezsi et al. 2013). These actions may be caused by epigenetic modifications. A study showing that children with absence epilepsy who receive ethosuximide are more likely than those who receive valproate to achieve longterm remission is consistent with the diseasemodifying actions observed in animal studies (Berg et al. 2014).

The efficacy of some other ASDs may also depend, at least in part, on actions at T-type calcium channels. Zonisamide, in addition to effects on voltage-gated sodium channels, may also block T-type voltage-gated calcium channels (Powell et al. 2014), thus accounting for its likely efficacy in absence epilepsy (Hughes 2009). Similarly, there is evidence that valproate, a drug of choice in absence epilepsy, may also inhibit T-type calcium channels (Broicher et al. 2007).

\section{$\mathrm{K}_{\mathrm{v}} 7$ Voltage-Gated Potassium Channels}

Voltage-gated potassium channels open in response membrane depolarization, permitting efflux of potassium ions, thus driving the membrane potential toward a hyperpolarized level. This serves to repolarize depolarizing events (such as action potentials and synaptic potentials) and cause a generalized reduction in excitability. In 1998, the first genes for a human idiopathic epilepsy were identified (Charlier et al. 1998). These genes, designated KCNQ2 and $K C N Q 3$, encoded novel brain potassium channel subunits, $K_{v} 7.2$ and $K_{v} 7.3$, respectively, which are homologous to a previously identified cardiac potassium channel $\mathrm{K}_{\mathrm{v}} 7.1$, encoded 
M.A. Rogawski et al.

by KCNQ1 (LQT1). These brain potassium channels mediate the $\mathrm{M}$ current, a potassium current that increases as the membrane potential in neurons approaches action potential threshold. $\mathrm{K}_{\mathrm{v}} 7$ channels, together with hyperpolarization-activated cyclic nucleotide-gated potassium (HCN) channels and small-conductance calcium-activated potassium $\left(\mathrm{K}_{\mathrm{Ca}} / \mathrm{SK}\right)$ channels, generate the medium after-hyperpolarization, which is elicited by a burst of action potentials and serves to limit further firing ( $\mathrm{Gu}$ et al. 2005). $\mathrm{K}_{\mathrm{v}} 7$ potassium channels also serve to counteract the spike after-depolarization generated by recruitment of $\mathrm{I}_{\mathrm{NaP}}$, which can lead to bursting (Yue and Yaari 2006). $\mathrm{K}_{\mathrm{v}} 7$ potassium channels, therefore, act as a "brake" on epileptic burst firing. The $\mathrm{K}_{\mathrm{v}} 7$ family of potassium channels is now known to contain five members, including $\mathrm{K}_{\mathrm{v}} 7.1$, which is expressed predominantly in the heart and $\mathrm{K}_{\mathrm{v}} 7.2-\mathrm{K}_{\mathrm{v}} 7.5$, which are expressed exclusively in the nervous system (Brown and Passmore 2009). Of these $\mathrm{K}_{\mathrm{v}} 7$ family members, $\mathrm{K}_{\mathrm{v}} 7.2$ and $\mathrm{K}_{\mathrm{v}} 7.3$ are highly expressed in neurons relevant to epilepsy, including principal (pyramidal) cells of the hippocampus and neocortex. Kv7.2 and Kv7.3 compose heterotetrameric channels in which four subunits are arranged around a potassium selective pore. $\mathrm{K}_{\mathrm{v}} 7.5$ channels may also contribute to $\mathrm{M}$ current and to neuronal after-hyperpolarization, for example, in the CA3 area of the hippocampus (Tzingounis et al. 2010).

Studies of the localization of $\mathrm{K}_{\mathrm{v}} 7.2$ and $\mathrm{K}_{\mathrm{v}} 7.3$ potassium channels by immunohistochemical techniques have indicated that the channels are present at highest density in axons and their terminals (Vacher et al. 2008). In myelinated fibers, they are present at nodes of Ranvier and the channels are also expressed at axon initial segments. In addition, the channels are expressed at lower levels in the somata of principal neurons and in some GABAergic neurons. Physiological studies in CA1 pyramidal neurons indicate that $\mathrm{K}_{\mathrm{v}} 7$ channels are functionally active in the perisomatic region ( $\mathrm{Hu}$ et al. 2007) and possibly also on distal dendrites (Yue and Yaari 2006).

Ezogabine (retigabine), which is efficacious in the treatment of focal seizures, acts as a pos- itive modulator of the nervous system $\mathrm{K}_{\mathrm{v}} 7$ potassium channels $\left(\mathrm{K}_{\mathrm{v}} 7.2-\mathrm{K}_{\mathrm{v}} 7.5\right)$, but does not affect the cardiac member of the family $\left(\mathrm{K}_{\mathrm{v}} 7.1\right)$ (Fig. 1). Of particular relevance to the antiseizure action of ezogabine is its action on the $\mathrm{M}$ current, which is predominantly carried by channels composed of $K_{v} 7.2$ and $K_{v} 7.3$, although $\mathrm{K}_{\mathrm{v}} 7.5$ alone or in combination with $\mathrm{K}_{\mathrm{v}} 7.3$ also contributes (Rogawski 2006; Gunthorpe et al. 2012). Ezogabine causes a hyperpolarizing shift in the activation of $\mathrm{K}_{\mathrm{v}} 7$ channels such that more $M$ current is generated near the resting potential. It also causes a change in the kinetics of single KCNQ channels to favor channel opening, thus increasing the macroscopic M current; ezogabine, nevertheless, does not alter the single channel conductance of individual $\mathrm{K}_{\mathrm{v}} 7$ channels (Tatulian and Brown 2003). As noted, many $\mathrm{K}_{\mathrm{v}} 7$ channels in the brain are believed to be $\mathrm{K}_{\mathrm{v}} 7.2 / \mathrm{K}_{\mathrm{v}} 7.3$ heteromers, and these are highly sensitive to ezogabine $\left(\mathrm{EC}_{50}\right.$, $1.6 \mu \mathrm{M}$ ) (Gunthorpe et al. 2012). Peak plasma levels of ezogabine range from 354 to $717 \mathrm{ng} / \mathrm{ml}$ $(1.2-2.4 \mu \mathrm{M})$ (Hermann et al. 2003), and plasma protein binding is $80 \%$ so that free plasma concentrations are estimated to be $\sim 0.2-$ $0.5 \mu \mathrm{M}$; brain concentrations are expected to be similar. Therefore, therapeutic concentrations likely only modestly potentiate the most sensitive $\mathrm{K}_{\mathrm{v}} 7$ channels and do not affect less sensitive channels. The binding site for ezogabine in $\mathrm{K}_{\mathrm{v}} 7.2 / \mathrm{K}_{\mathrm{v}} 7.3$ heteromers is in a pocket formed by the pore-lining S5 membrane segment of one subunit and the pore-lining S6 membrane segment of the neighboring subunit (Wuttke et al. 2005; Lange et al. 2009). Channel opening may expose the pocket, permitting binding of ezogabine, which stabilizes the open channel conformation.

Several experimental approaches support the role of $\mathrm{K}_{\mathrm{v}} 7$ potassium channels in the antiseizure activity of ezogabine. Mice with a genetic defect in these channels show reduced sensitivity to the antiseizure effect of ezogabine (Gunthorpe et al. 2012). Furthermore, the KCNQ inhibitor, XE-991, partially blocks the antiseizure effect of ezogabine in an electrical seizure test (Gunthorpe et al. 2012). However, the precise way in which activation of $\mathrm{K}_{\mathrm{v}} 7$ chan- 
nels leads to seizure protection remains to be elucidated. Consistent with the presynaptic localization of many $\mathrm{K}_{\mathrm{v}} 7$ channels, ezogabine has been found to inhibit the release of various neurotransmitters, including GABA and probably also glutamate (Martire et al. 2004). Inhibition of glutamate release is expected to confer seizure protection. The impairment of GABA release or the direct inhibition of inhibitory interneurons (Lawrence et al. 2006; Grigorov et al. 2014) would be expected to enhance circuit excitability. Indeed, in rodents, retigabine shows proconvulsant activity at doses $(\geq 61.9 \mathrm{mg} / \mathrm{kg})$ that are approximately 10 -fold greater than those associated with seizure protection (U.S. Food and Drug Administration 2010). Paradoxically, and in contrast to biochemical observations, physiological studies have found that ezogabine "increases" glutamate-mediated synaptic transmission in the hippocampus through a presynaptic action by reducing the inactivation of voltage-gated sodium channels so that sodium-dependent action potentials are elicited with greater probability (Vervaeke et al. 2006). This action could contribute to the proconvulsant effects of the drug. If ezogabine does confer seizure protection through effects on excitatory neurons, postsynaptic actions to inhibit somatic excitability likely predominate.

In addition to its effects on $\mathrm{K}_{\mathrm{v}} 7$ potassium channels, ezogabine has been reported to interact with the GABA system. At high concentrations $(>10 \mu \mathrm{M})$, ezogabine was shown to potentiate GABA-mediated inhibitory transmission by acting as a positive allosteric modulator of $\mathrm{GABA}_{\mathrm{A}}$ receptors (Rundfeldt and Netzer 2000; Otto et al. 2002). Recent evidence that inhibitory effects of the drug on seizure-like activity in hippocampal neurons persist in the presence of blockade of $\mathrm{K}_{\mathrm{v}} 7$ channels has bolstered the view that positive modulation of $\mathrm{GABA}_{\mathrm{A}}$ receptors could be key to its antiseizure activity (Treven et al. 2015). Thus, at lower concentrations than are required for effects on synaptic $\mathrm{GABA}_{\mathrm{A}}$ receptors, ezogabine selectively enhances extrasynaptic $\mathrm{GABA}_{\mathrm{A}}$ receptors that contain the $\delta$-subunit (Treven et al. 2015). Ezogabine has also been reported to increase GABA synthesis (Kapetanovic et al. 1995); the mecha- nism and implications of this effect are not known. In sum, various lines of evidence raise the possibility that effects of ezogabine on GABA mechanisms could be of importance in its antiseizure activity.

\section{GABA INHIBITION}

GABA, the neurotransmitter of local inhibitory interneurons, acts through $\mathrm{GABA}_{\mathrm{A}}$ and $\mathrm{GABA}_{\mathrm{B}}$ receptors. $\mathrm{GABA}_{\mathrm{A}}$ receptors, which are Cys loop-type ligand-gated chloride channels, represent an important target for ASDs and will be considered here. $G_{A B A}$ receptors, which are heterodimeric G-protein-coupled receptors that activate potassium channels and inhibit calcium channels, are distinct in structure and function from $\mathrm{GABA}_{\mathrm{A}}$ receptors and are not a target of any ASD. Although only about one in five cortical neurons is GABAergic (Sahara et al. 2012), these neurons play a critical role in controlling the firing rate and timing of principal (excitatory) neurons. In addition, they synchronize local neuronal ensembles and restrain the generation of abnormal epileptic behavior. Consequently, enhancement of GABAergic inhibition is a key mechanism of ASD action.

\section{$\mathrm{GABA}_{\mathrm{A}}$ Receptors}

$\mathrm{GABA}_{\mathrm{A}}$ receptors are heteropentameric protein complexes localized to the postsynaptic membrane of inhibitory synapses (Fig. 2) where they mediate fast neuronal inhibition on a millisecond timescale. They are also located extrasynaptically where they respond to ambient GABA in the extracellular milieu and confer tonic (longterm) inhibition. There are 19 known $\mathrm{GABA}_{\mathrm{A}}$ receptor subunits $(\alpha 1-6, \beta 1-3, \gamma 1-3, \delta, \varepsilon, \theta$, $\pi$, and $\rho 1-3$ ) (Olsen and Sieghart 2009). However, the bulk $(60 \%)$ of synaptic $\mathrm{GABA}_{\mathrm{A}}$ receptors are believed to have the $\alpha 1 \beta 2 \gamma 2$ configuration, and a considerable fraction of the remainder $(15 \%-20 \%)$ has $\alpha 2 \beta 3 \gamma 2$. Among the receptor subtypes that contribute to tonic signaling in brain regions relevant to epilepsy are $\alpha 4 \beta \times \delta \delta$ receptors, which are believed to mediate the tonic current in dentate granule cells and thalamocortical neurons, and $\alpha 5$-contain- 
M.A. Rogawski et al.

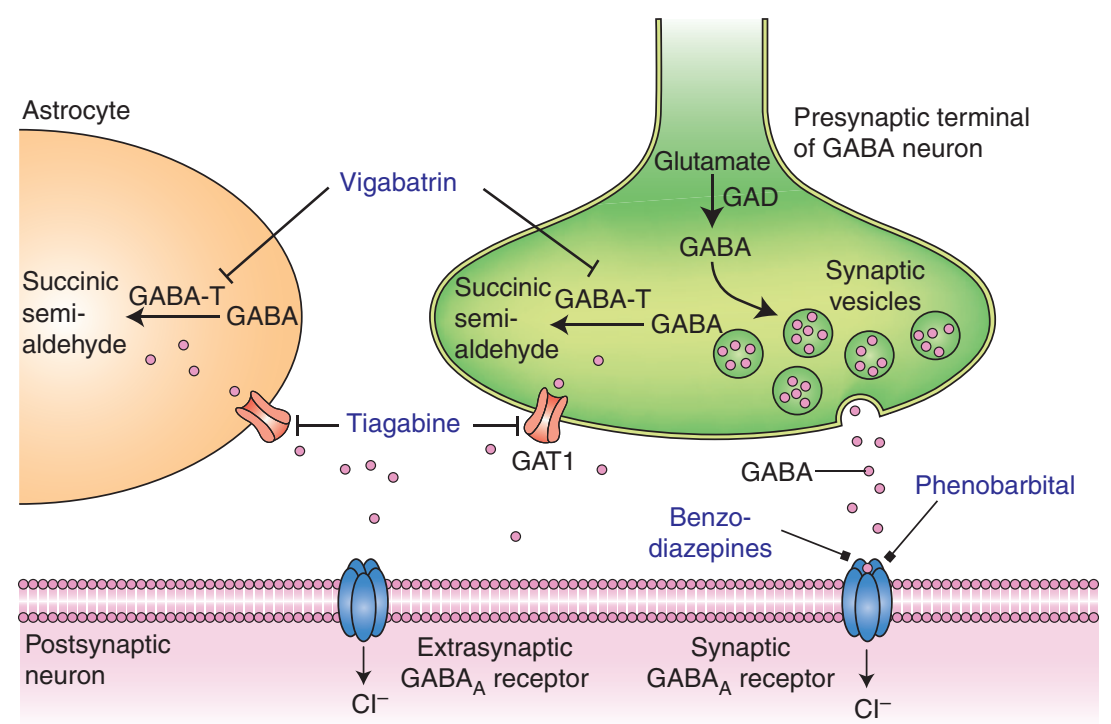

Figure 2. Diverse molecular targets for antiseizure drugs (ASDs) at inhibitory $\gamma$-aminobutyric acid (GABA)ergic synapses. Seizure protection can be conferred by effects on synaptic or extrasynaptic $\mathrm{GABA}_{\mathrm{A}}$ receptors or on GABA transaminase (GABA-T) or GABA transporter 1 (GAT1). Furthermore, some ASDs (e.g., valproate) have been shown to increase the activity of the GABA-synthesizing enzyme glutamic acid decarboxylase (GAD), thereby increasing GABA turnover. Astrocytes contain elements, including GABA transporters, which influence the dynamics of GABA, thereby affecting the excitability of the postsynaptic neuron.

ing $\mathrm{GABA}_{\mathrm{A}}$ receptors in CA1 pyramidal cells (Walker and Kullmann 2012).

Benzodiazepines, such a diazepam, lorazepam, and clonazepam, and barbiturates, such as phenobarbital (Löscher and Rogawski 2012), are ASDs that act on $\mathrm{GABA}_{\mathrm{A}}$ receptors as positive allosteric modulators (Fig. 2). At higher concentrations, barbiturates can directly activate $\mathrm{GABA}_{\mathrm{A}}$ receptors in the absence of GABA (Rho et al. 1996), whereas benzodiazepines cannot. Benzodiazepines are specific for synaptic $\mathrm{GABA}_{\mathrm{A}}$ receptors containing the $\gamma 2$ subunit and act to allosterically modulate these receptors to increase the channel-opening frequency, resulting in enhanced synaptic inhibition. This confers a broad-spectrum antiseizure action. In most epilepsy syndromes, the specific cellular types that are involved in the antiseizure activity of benzodiazepines are not known. However, in the case of absence epilepsy, it is believed that benzodiazepines desynchronize the thalamocortical oscillations underlying generalized spike-wave discharges by specific effects on $\alpha 3$-containing $\mathrm{GABA}_{\mathrm{A}}$ receptors in the thalamic reticular nucleus (Sohal et al. 2003). Barbiturates, presumably because they are not specific for $\alpha 3$-containing $\mathrm{GABA}_{\mathrm{A}}$ receptors, are not active in absence epilepsy and may even aggravate absence seizures. In contrast to benzodiazepines, barbiturates do not appear to increase the frequency of GABA-induced chloride channel opening, but instead increase the channel open time. In addition to effects on $\mathrm{GABA}_{\mathrm{A}}$ receptors, barbiturates modulate other ion channel systems, including calcium and sodium channels, and these actions may contribute to therapeutic activity (ffrench-Mullen et al. 1993).

\section{GAT1 GABA Transporter}

The action of the neurotransmitter GABA is terminated by uptake into neurons and glial cells by membrane-bound GABA transporters, of which there are four types, termed GAT1, BGT1, GAT2, and GAT3. GAT1 (encoded by the SLC6A1 gene), the predominant form in the forebrain (including the neocortex and hip- 
pocampus), is localized to GABAergic terminals, as well as to glial processes near GABA synapses (Fig. 2). Tiagabine is a highly selective inhibitor of GAT1 in neurons and glia (Schousboe et al. 2014). Inhibition of GAT1 by tiagabine suppresses the translocation of extracellular GABA into the intracellular compartment, thus raising extracellular GABA levels. Functionally, tiagabine prolongs GABA-mediated inhibitory synaptic responses (Thompson and Gähwiler 1992) and the marked elevation in extracellular GABA it produces may lead to activation of extrasynaptic GABA receptors.

\section{GABA Transaminase}

4-Aminobutyrate aminotransferase (GABA transaminase), an enzyme that catalyzes the conversion of GABA and 2-oxoglutarate into succinic semialdehyde and glutamate, is responsible for the metabolic inactivation of GABA (Fig. 2). Inhibition of GABA transaminase with vigabatrin ( $\boldsymbol{\gamma}$-vinyl GABA), an irreversible suicide inhibitor of the enzyme, leads to marked increases in brain GABA levels (Petroff et al. 1996). Although the antiseizure action of vigabatrin is believed to reflect inactivation of GABA transaminase, how this occurs is not straightforward and does not appear to be caused by an enhancement of inhibitory synaptic transmission. In contrast to the action of tiagabine, vigabatrin does not elicit larger or more prolonged $\mathrm{GABA}_{\mathrm{A}}$ receptor-mediated synaptic responses (Overstreet and Westbrook 2001; Wu et al. 2003). Rather, preincubation of brain slices with vigabatrin irreversibly inhibited miniature and evoked inhibitory postsynaptic currents. Additional experiments suggested that the paradoxical effect resulted from a reduction in the GABA content of synaptic vesicles caused by GABA transaminase inhibition. In contrast to the effect on GABA-mediated synaptic transmission, vigabatrin caused an increase in tonic (nonsynaptic) $\mathrm{GABA}_{\mathrm{A}}$ receptor current. This steady current is believed to be mediated by the action of GABA in the extracellular milieu acting on extrasynapic $\mathrm{GABA}_{\mathrm{A}}$ receptors. High levels of intracellular GABA cause a reversal of GABA transporters, resulting in a marked ele- vation in extracellular GABA, which is likely responsible for the increase in tonic $\mathrm{GABA}_{\mathrm{A}}$ receptor current. It can be concluded that vigabatrin causes divergent effects on synaptic and extrasynaptic GABA-mediated inhibition with seizure protection resulting from a predominance of the extrasynaptic action. Interestingly, in the early period after administration of vigabatrin to animals, there is a reduction in seizure threshold, whereas the antiseizure actions become evident only later (Löscher et al. 1989; Stuchlík et al. 2001). Thus, vigabatrin has a biphasic action with proconvulsant effects likely related to suppression of synaptic GABAergic neurotransmission and antiseizure effects as a result of spillover of GABA into the extracellular space and activation of extrasynaptic $\mathrm{GABA}_{\mathrm{A}}$ receptors. Interestingly, individuals with a rare genetic deficiency of GABA transaminase experience refractory seizures, supporting the view that inhibition of GABA transaminase is, in fact, the proconvulsant mechanism of vigabatrin (Medina-Kauwe et al. 1999).

\section{SYNAPTIC RELEASE MACHINERY}

\section{SV2A}

Multiple lines of evidence support the conclusion that SV2A, a membrane glycoprotein found in the secretory vesicles of neurons and endocrine cells and possibly immune cells, is the molecular target for levetiracetam (Kaminski et al. 2012; Li et al. 2013). There is a strong correlation between the affinity of levetiracetam analogs for binding to SV2A and the potency of the analogs in several animal seizure models. Moreover, seizure protection conferred by levetiracetam and other SV2A ligands strongly correlates with the degree of SV2A occupancy in vivo. Finally, the antiseizure efficacy of levetiracetam (but not valproate, which does not interact with SV2A) is reduced in $\mathrm{SV} 2 \mathrm{~A}^{+/-}$mice that have one copy of SV2A disrupted by gene targeting. The precise way in which binding of levetiracetam to SV2A leads to seizure protection is not understood.

Indeed, the function of SV2A itself is obscure. Among the various functions proposed 
M.A. Rogawski et al.

are roles in calcium-dependent exocytosis, neurotransmitter loading/retention in synaptic vesicles, and synaptic vesicle priming, as well as transport of vesicle constituents. SV2A is one of three homologous SV2 proteins that belong to the major facilitator superfamily of 12-transmembrane domain transporters. Despite substantial effort, no transport function of these proteins has yet been identified, although studies with protein tomography have found that SV2A can adopt two alternate conformations consistent with a transporter role (Lynch et al. 2008). Interestingly, however, levetiracetam binding does not cause a large-scale conformational change in SV2A, or lock a specific conformational state of the protein, as would an inhibitor of transport. Apparently, the drug has a more subtle effect on the protein. Although the function of SV2A is still poorly defined, SV2A ${ }^{-/-}$knockout mice show a lethal seizure phenotype demonstrating that SV2A, in some way, serves to restrain seizure activity.

A series of recent studies has examined the impact of levetiracetam on synaptic transmission in brain slice recordings (Meehan et al. 2011, 2012). Although the drug had no effect on synaptic physiology with low frequency activation, levetiracetam did reduce the synaptic release of both excitatory (glutamate) and inhibitory (GABA) neurotransmitters during high-frequency activation. The frequency dependence is compatible with the selective suppression of epileptic activity. Modulation of synaptic release is a common mechanism of many ASDs, including sodium-channel blockers, which indirectly inhibit release at both excitatory and inhibitory synapses by inhibiting action potential firing. It appears that drugs that suppress inhibition and excitation can effectively protect against seizures, and they are not often proconvulsant. However, it is noteworthy that in some instances ASDs (notably, phenytoin) can have proconvulsant effects, particularly at high doses.

With several seconds of heavy use, as likely occurs during epileptic activity, excitatory synapses undergo a form of short-term plasticity that is dependent on the supply of new vesicles referred to as "supply-rate depression" (García-
Pérez et al. 2008). This form of synaptic depression is distinct from that mediated by depletion of the readily releasable pool of vesicles and is not believed to come into play during ordinary ongoing activity. It may, however, limit synaptic transmission during sustained high-frequency firing and thus serve as an endogenous mechanism to restrain epileptic activity. It is, therefore, of interest that levetiracetam has been shown to cause a small acceleration of supply rate depression (García-Pérez et al. 2015). This effect was observed in experiments with mouse hippocampal CA1 neurons activated by Schaffer collateral stimulation in brain slices and also in hippocampal neurons in culture, but not in cultured neurons from mice lacking SV2A, indicating that an interaction of levetiracetam with SV2A is likely to account for the phenomenon. Thus, work in various laboratories raises the possibility that levetiracetam confers seizure protection through an interaction with SV2A by reducing synaptic release in a use-dependent fashion that requires high-frequency activation for prolonged periods.

With respect to the specificity of levetiracetam's effect on SV2A, it is important to note that several other cellular and molecular effects of this ASD have been reported at therapeutically relevant concentrations, including inhibition of high-voltage-gated calcium channels, inhibition of calcium release from intraneuronal stores, effects on the metabolism and turnover of GABA in discrete brain regions, reduction in the firing activity of GABAergic neurons in substantia nigra pars reticulata in vivo, and reversal of zinc-induced inhibition of $\mathrm{GABA}_{\mathrm{A}}$ receptors in epileptic tissue (Löscher et al. 1996; Lyseng-Williamson 2011; Wakita et al. 2014). The relevance of any of these various pharmacological actions to the antiseizure effect of levetiracetam remains to be defined.

\section{$\alpha 2 \delta-1$}

The gabapentinoids gabapentin and pregabalin act by binding to the $\alpha 2 \delta-1$ protein, which is an accessory subunit of voltage-gated calcium channels (Dolphin 2013; Stahl et al. 2013). $\alpha 2 \delta-1$ is located heterogeneously in the brain, 
particularly, at presynaptic sites on excitatory (glutamatergic) neurons. Dense expression is observed in areas relevant to epilepsy, including in excitatory hippocampal mossy fibers and in the neocortex and amygdala. In contrast, $\alpha 2 \delta-1$ has minimal expression in the thalamus and it is noteworthy that gabapentinoids are not active in absence seizures, which, as discussed above, are dependent on this brain structure. Four $\alpha 2 \delta$ subunits have been identified, but gabapentinoids only bind to $\alpha 2 \delta-1$ and $\alpha 2 \delta-2$ owing to the presence of an RRR motif containing a critical arginine that is required for binding. In knock-in mutant mice bearing a mutation in this motif (RRR mutated to RRA) in $\alpha 2 \delta-1$, which eliminates gabapentin and pregabalin binding, the analgesic and anxiolytic-like activity of pregabalin is eliminated (Field et al. 2006; Lotarski et al. 2011). A corresponding mutation in $\alpha 2 \delta-2$, which also eliminates binding, has no similar effect on the anxiolytic-like activity of pregabalin demonstrating that $\alpha 2 \delta-1$ and not $\alpha 2 \delta-2$ is relevant for its pharmacological activity; studies to determine whether binding to $\alpha 2 \delta-1$ and not $\alpha 2 \delta-2$ is necessary and sufficient to account for the antiseizure activity of gabapentinoids have not been reported. Interestingly, deletion of $\alpha 2 \delta-1$ or $\alpha 2 \delta-2$ in mice is associated with absence epilepsy or enhanced seizure susceptibility (Ivanov et al. 2004; Davies et al. 2007).

The precise manner in which binding of gabapentin and pregabalin to the $\alpha 2 \delta$ - 1 protein results in its pharmacological activity, including seizure protection, is not well understood (Rogawski and Bazil 2008). Although some studies have found that the drugs inhibit calcium channel currents, most have not and it is generally believed that calcium channel inhibition is not the mechanism of action of gabapentinoids (Stefani et al. 1998; van Hooft et al. 2002; Brown and Randall 2005). Regardless of whether the drugs inhibit calcium channel function, they do seem to block the release of various neurotransmitters, including glutamate, and this may account for the antiseizure activity (Dooley et al. 2007). There is some evidence that gabapentinoids cause internalization of calcium channels by reducing trafficking to the cell membrane (Hendrich et al. 2008; Weissmann et al. 2013). Whether this action could account for the rapid antiseizure effects of gabapentinoids in animal models is uncertain.

Gabapentin and pregabalin were initially developed as lipophilic, blood-brain barrier permeable forms of GABA (3-alkylated GABA analogs), but it is generally accepted that effects on GABA do not contribute to the pharmacological action of these drugs (Taylor et al. 2007). However, the gabapentinoids do activate the GABA-synthesizing enzyme glutamic acid decarboxylase (GAD) (Silverman et al. 1991) and elevate GABA turnover at antiseizure doses in rats (Löscher et al. 1991) and patients with epilepsy (Petroff et al. 1996). Interestingly, the activating effects of the gabapentinoids on GAD and GABA turnover were similar to those reported for valproate (Löscher 1989; Silverman et al. 1991; Taylor et al. 1992).

\section{AMPA RECEPTORS}

Of the synapses in the brain, $80 \%-90 \%$ are excitatory (Hassel and Dingledine 2012). At these synapses, which are often between the presynaptic terminal of an excitatory neuron and a dendritic spine of the postsynaptic neuron, neurotransmitter glutamate released from the presynaptic terminal acts on ionotropic (ion flux conducting) and metabotropic (nonion flux conducting, G-protein-coupled) glutamate receptors localized to the postsynaptic density. Ionotropic glutamate receptors mediate a fast (millisecond timescale) depolarization of the postsynaptic neuron, referred to as the excitatory postsynaptic potential (EPSP). AMPA receptors, one type of ionotropic glutamate receptor, generate the bulk of the EPSP and are therefore the principal ion channel responsible for fast synaptic excitation. It has been long appreciated that cascading excitation within networks of synaptically connected neurons is a key mechanism of epileptic synchronization, at least in the hippocampal CA3 subfield and, possibly, in other brain areas (Rogawski 2013). Epileptic activity emerges from the network when GABA-mediated inhibition is deficient and, indeed, chronic alterations in inhibition 
M.A. Rogawski et al.

represent a leading hypothesis to explain some forms of epilepsy (Houser 2014). AMPA receptors have a special role in epileptic activity as epileptic synchronization cannot occur when AMPA receptors are blocked. In contrast, kainate receptors, which are ionotropic glutamate receptors that have a similar structure to AMPA receptors, do not have a similarly essential role as kainate receptor knockout does not interfere with seizure generation (Fritsch et al. 2014). NMDA receptors are thought to contribute to epileptiform activity, but the blockade of NMDA receptors is insufficient to abolish epileptiform discharges in many seizure models (Neuman et al. 1988; Löscher 1998). Moreover, NMDA blockers may exacerbate seizures in humans (Sveinbjornsdottir et al. 1993; Kasteleijn-Nolst Trenité et al. 2015). Pharmacological blockade of AMPA receptors has broad spectrum antiseizure activity in in vitro and animal seizure and epilepsy models (Yamaguchi et al. 1993; Rogawski 2011; Twele et al. 2015). In neocortical and hippocampal tissue removed from patients with focal epilepsy, there is evidence that AMPA receptor density is increased (Mathern et al. 1998; Zilles et al. 1999; Eid et al. 2002). Thus, it has been proposed that the hyperexcitability in focal epilepsy, in part, relates to strengthened excitatory circuits because of increased expression of AMPA receptors. AMPA receptors may therefore be a pivotal pharmacological target for the control of seizures.

Perampanel, a potent noncompetitive AMPA receptor antagonist, is the first and at present only antiseizure agent available for clinical use that selectively targets AMPA receptors (Fig. 1). Perampanel does not affect NMDA receptor responses and has no known effects on other ion channels or molecular targets at therapeutically relevant concentrations (Hanada et al. 2011; Chen et al. 2014). Therapeutic blood levels are expected to result in brain concentrations that would produce only low levels of inhibition of AMPA receptors (Rogawski and Hanada 2013). However, such low-level block of AMPA receptors is apparently sufficient to exert a clinical antiseizure action. Perampanel has a relatively low therapeutic window. Adverse central nervous system effects, such as dizziness, irritability, and somnolence, are common, particularly at higher doses, emphasizing the importance of AMPA receptors in brain function. Although AMPA receptor antagonists have powerful antiseizure effects, they are not antiepileptogenic in animal models (Rogawski et al. 2001; Twele et al. 2015).

Secondarily generalized tonic-clonic seizures and, probably, also primary generalized tonic-clonic seizures engage distant regions in the cerebral cortex, as well as subcortical structures including thalamus, cerebellum, and basal ganglia (Blumenfeld et al. 2009). Glutamatergic neurons are responsible for the spread of excitation to these structures and also for thalamocortical projections that synchronize distant cortical sites. As is the case at glutamate synapses, generally, AMPA receptors generate the bulk of the excitatory current during fast synaptic transmission in these pathways (Turner and Salt 1998). The involvement of AMPA receptors in long cortical-cortical and cortical-subcortical pathways, which mediate the spread of excitation in generalized seizures, is likely the basis for the effectiveness of AMPA receptor antagonists in the treatment of secondarily generalized (Steinhoff et al. 2013) and primary generalized tonic-clonic seizures, and also in suppressing the generalized photoparoxysmal electroencephalography (EEG) response in patients with photosensitive epilepsy (Kasteleijn-Nolst Trenité et al. 2015).

\section{MIXED TARGETS}

\section{Valproate}

Although valproate is one of the most widely prescribed ASDs, the mechanism by which it protects against seizures is poorly understood. Valproate has multiple pharmacological actions (Rogawski and Porter 1990; Löscher et al. 2002). Because it has been difficult to relate any one mechanism to the drug's broad spectrum of clinical activity, it has been proposed that combined actions on several targets could account for its therapeutic properties. Although the actions of valproate on GABA systems are not straightforward, among the various pharmacological effects that have been described, those 
related to GABA mechanisms are among the most likely to be relevant to valproate's antiseizure activity. For example, valproate increases the turnover of GABA in a regionally selective manner (Löscher 1989) and this might be associated with enhanced synaptic or extrasynaptic inhibition. At high concentrations, valproate affects voltage-gated sodium channels, but recent studies in brain slice recordings have failed to provide support for sodium-channel block as a relevant mechanism to explain clinical activity (Englund et al. 2011). Similarly, despite efficacy in absence epilepsy, there is little support for effects on T-type calcium channels. It is clear that valproate has pharmacological actions relevant to its antiseizure activity that remain to be elucidated.

\section{Felbamate}

Felbamate has been shown to act both as a positive modulator of $\mathrm{GABA}_{\mathrm{A}}$ receptors and also to inhibit NMDA receptors (Rho et al. 1994). Felbamate potentiates GABA responses via an interaction with a site on the $\mathrm{GABA}_{\mathrm{A}}$ receptor that is distinct from the benzodiazepine recognition site. This action may be of relevance to felbamate's clinical activity. As discussed above, NMDA receptors have not been validated as a target to treat focal or generalized seizures. Therefore, it is uncertain whether the NMDAreceptor-blocking activity of felbamate is relevant to its clinical antiseizure activity.

\section{Topiramate}

Topiramate shows a variety of pharmacological actions, but the extent to which any of the actions are relevant to its broad-spectrum antiseizure activity is uncertain. Targets potentially relevant to seizure protection include voltagegated sodium channels, $\mathrm{GABA}_{\mathrm{A}}$ receptor subtypes, AMPA or kainate receptors, and types II and IV carbonic anhydrase isoenzymes. Unlike other ASDs, the effects on ion channels are not likely to occur through direct modulation of channel gating. Rather, the pharmacological actions of topiramate seem to be mediated indirectly, possibly through effects on channel phosphorylation (Shank et al. 2008).
The effects of topiramate on sodium channels occur at relatively low, therapeutically relevant concentrations and could be similar to the effects of other sodium-channel-blocking ASDs (Avoli et al. 1996). In addition to effects on fast sodium currents, topiramate, like phenytoin, blocks $\mathrm{I}_{\mathrm{NaP}}$ at low concentrations (Sun et al. 2007). Effects of topiramate on $\mathrm{GABA}_{\mathrm{A}}$ receptors could contribute to the broad spectrum activity of topiramate. Topiramate is not active in animal models, such as the pentylenetetrazol (PTZ) test, which are typically sensitive to drugs that positively modulate $\mathrm{GABA}_{\mathrm{A}}$ receptors. Nevertheless, the drug does have activity in an absence of epilepsy models (Rigoulot et al. 2003) and can affect pentylenetetrazol threshold, which is consistent with effects on $\mathrm{GABA}_{\mathrm{A}}$ receptors. There is evidence that topiramate may preferentially modulate a subset of $\mathrm{GABA}_{\mathrm{A}}$ receptors and that drug sensitivity is dependent on the $\beta$-subunit type (Simeone et al. 2011).

Several investigators have suggested that actions on fast glutamate-mediated excitatory neurotransmission could contribute to topiramate's antiseizure activity. In cultured neurons, the drug has been reported to inhibit responses to kainate, an agonist of AMPA and kainate receptors, leading to the conclusion that topiramate could be an antagonist of either AMPA or kainate receptors (Gibbs et al. 2000). Recently, kainate receptors have been found to be an unlikely target for an antiseizure agent (Fritsch et al. 2014). Whether actions of topiramate on glutamate-mediated neurotransmission contribute to its antiseizure activity remains to be determined.

It has been assumed that the topiramate's inhibition of carbonic anhydrase does not contribute to its clinical efficacy because there is no cross-tolerance to the antiseizure activity of topiramate when tolerance occurs to the classical carbonic anhydrase inhibitor acetazolamide in mice. However, a recent review left open the possibility that carbonic anhydrase inhibition could, in part, play a role (Shank and Maryanoff 2008).

Topiramate is well recognized to cause adverse cognitive effects, including impairment of working memory and verbal fluency. A blood- 
M.A. Rogawski et al.

concentration-dependent decline in phonemic generative fluency has been shown, but the basis for this effect is not understood (Ahmed et al. 2015).

\section{Zonisamide}

There are some similarities between topiramate and zonisamide as they both contain a sulfur atom and both inhibit carbonic anhydrase. In addition, like topiramate, zonisamide may act on voltage-gated sodium channels (Biton 2007). Electrophysiological studies, however, do not support an action on $\mathrm{GABA}_{\mathrm{A}}$ receptors. Unlike topiramate, there are reports that zonisamide can inhibit T-type voltage-gated calcium channels (Matar et al. 2009), which as stated above may account for its activity in absence epilepsy.

\section{Rufinamide}

The unique spectrum of clinical activity of rufinamide in the treatment of Lennox-Gastaut syndrome (a highly medically intractable epileptic encephalopathy) suggests that it has a distinct mechanism of action (Rogawski 2006). However, to date, rufinamide has only been shown to interact with voltage-gated sodium channels and the effects are subtle. Relevant concentrations of the drug may, at least for some subunit isoforms, cause a depolarization in the activation voltage and slowing of recovery from inactivation, which would be expected to reduce neuronal excitability (Gilchrist et al. 2014). Clearly, the effects on sodium channels cannot explain the special clinical profile of rufinamide.

\section{Adrenocorticotrophin}

The mechanism of adrenocorticotrophin $(\mathrm{ACTH})$ in the treatment of infantile spasms is not well understood (Stafstrom et al. 2011). ACTH stimulates glucocorticoid (cortisol) synthesis and release from the zona fasciculata of the adrenal cortex. The cortisol could produce an anti-inflammatory action or have some other action in the brain to influence infantile spasms. Indeed, glucocorticoids are well recognized themselves and have therapeutic activity in the treatment of infantile spasms; whether $\mathrm{ACTH}$ is truly superior remains to be shown conclusively. One possible additional action of ACTH that could contribute to an enhanced action is through stimulation of neurosteroid synthesis. In addition to its actions with respect to glucocorticoids, ACTH also stimulates deoxycorticosterone (DOC) release from the zona glomerulosa of the adrenal cortex. DOC is, in part, converted to the antiseizure neurosteroid tetrahydro-DOC, which is a positive allosteric modulator of $\mathrm{GABA}_{\mathrm{A}}$ receptors (Reddy and Rogawski 2002). It has been hypothesized that the tetrahydro-DOC could, at least in part, contribute to the ability of ACTH to terminate infantile spasms.

\section{KETOGENIC DIET}

The use of dietary manipulations to treat epilepsy-in particular, controlling seizures through sustained fasting-dates back to the time of Hippocrates (Lennox and Cobb 1928; Wheless 2008). In the early 1920s, investigators realized that a diet composed principally of fats could be as effective as fasting and yield longterm suppression of seizures without severe caloric deprivation. Thus was born the ketogenic diet whose hallmark feature is the production of ketone bodies ( $\beta$-hydroxybutyrate, acetoacetate, and acetone) by the liver (Peterman 1924; Freeman and Kossoff 2010). In an era before the availability of safe and effective ASDs, the ketogenic diet quickly became popular in large medical centers. However, with the advent of phenytoin in 1938, the ketogenic diet quickly fell out of favor mainly because the oral medication was simpler than the strict and exacting dietary regimen. Beginning in the mid-1990s, there was a resurgence of interest in the ketogenic diet as it was increasingly recognized that the diet has utility in the treatment of drug-resistant epilepsy (Freeman and Kossoff 2010). Today, the ketogenic diet is an established therapy for difficult-to-treat epilepsies, particularly in children, and is increasingly being studied for therapeutic efficacy in a number of other neurological disorders (Gasior et al. 2006; Neal et al. 2008; Stafstrom and Rho 2012). 
Scientific interest in the mechanisms by which the ketogenic diet exerts seizure control has evolved rapidly in parallel with the growth in clinical use of the diet over the past 20 years (Masino and Rho 2012). Effectiveness of the ketogenic diet has been amply shown in animal models of seizures and epilepsy. Still, at present, the basic mechanisms of ketogenic diet action remain incompletely understood. There is substantial interest in defining these mechanisms. Dietary therapy is not feasible for many patients, but the insights gained from study of the diet may provide clues to the creation of more effective ASDs to address pharmacoresistant epilepsy. Since the 1930s, numerous mechanistic hypotheses have been advanced to explain the antiseizure effects of the ketogenic diet; the key mechanisms are discussed below and summarized in Table 2.

\section{Direct Effects of Ketone Bodies}

The earliest demonstration that ketone bodies have antiseizure properties was given in the 1930s. Acetoacetate was shown to protect against thujone-induced seizures in rabbits (Keith 1933). Further, acetone was shown to exert antiseizure activity in several animal models (Likhodii et al. 2003; Gasior et al. 2007). Recently, chronic administration of the major ketone, $\beta$-hydroxybutyrate, was shown to block spontaneous seizures in epileptic mice (Kim et al. 2015). Interestingly, the in vivo evidence for the antiseizure effects of ketone bodies has been discordant with earlier in vitro studies. Application of acetoacetate or $\beta$-hydroxybutyrate in acute hippocampal brain slices from normal rats failed to reveal effects on $\mathrm{GABA}_{\mathrm{A}}$ receptors and ionotropic glutamate receptors, and on synaptic transmission (Thio et al. 2000). However, more recent data indicate that the antiseizure activity of ketone bodies in vitro may require long-term incubation and not simply acute exposure (Kim et al. 2015). Collectively, it appears that ketone bodies afford broad spectrum antiseizure activity in animal models and, hence, the possibility that these metabolites contribute to the therapeutic efficacy of the diet cannot be discounted. Although the molecular targets through which ketone bodies act to protect against seizures have not yet been clearly identified, there is strong evidence to suggest that mitochondria are critically involved (Masino and Rho 2012). Also, given that the ketogenic diet is mainly used in younger patients, enhanced efficacy in this population could reflect age-dependent changes in the expression of monocarboxylate transporters, which import ketone bodies across the bloodbrain barrier from the systemic circulation (Morris 2005; Pierre and Pellerin 2005).

\section{Effects on GABA and Glutamate Metabolism}

It has been proposed that increased synthesis or levels of the inhibitory neurotransmitter GABA or decreased synthesis or levels of the excitatory neurotransmitter glutamate could explain the antiseizure activity of the ketogenic diet. The implication of such findings is uncertain inasmuch as it has not been shown that these manipulations influence neural circuit excitability, either through synaptic or nonsynaptic actions. Nevertheless, we summarize the results of some of these studies to illustrate the kinds of observations that have been reported.

The influence of the ketogenic on GABA has been proposed to originate in changes in glutamate metabolism (Yudkoff et al. 2005). Glutamate is cleared from the synaptic space by astrocytes, which convert glutamate to glutamine through the action of the glial enzyme glutamine synthetase. Glutamine is then exported to neurons where it is hydrolyzed to glutamate and can then either be converted to GABA or transaminated to aspartate in a reaction that requires oxaloacetate. Because the ketogenic diet induces metabolic changes that require available oxaloacetate to condense with acetylCoA for incorporation into the tricarboxylic acid (TCA) cycle, the production of aspartate from glutamate is reduced. This may result in enhanced flux through GAD to increase the synthesis of GABA.

Experimental support for this biochemical hypothesis is mixed. In the study proposing the hypothesis, which used a mouse model of ketosis, changes in levels of aspartate were found, 
M.A. Rogawski et al.

Table 2. Putative mechanisms of the antiseizure effects of the ketogenic diet

\begin{tabular}{|c|c|c|}
\hline Mediator/physiological change & Basis & Mechanism of antiseizure effects \\
\hline $\begin{array}{l}\text { Ketone bodies (acetone, } \\
\text { acetoacetate, and } \beta \text { - } \\
\text { hydroxybutyrate have } \\
\text { antiseizure activity; further, } \\
\text { acetoacetate, and } \beta \text { - } \\
\text { hydroxybutyrate provide } \\
\text { resistance to oxidative stress) }\end{array}$ & $\begin{array}{l}\text { Chronic ketosis as a result of } \\
\text { elevated FFAs }\end{array}$ & $\begin{array}{l}\text { Unknown } \\
\text { ? Inhibit presynaptic release of } \\
\text { glutamate by competing with } \\
\mathrm{Cl}^{-} \text {for allosteric activation of } \\
\text { vesicular glutamate transporter } \\
\text { ? Activate } \mathrm{K}_{\mathrm{ATP}} \text { and GABA } \mathrm{B}_{\mathrm{B}} \\
\text { receptors (reduced ATP also } \\
\text { activates } \mathrm{K}_{\mathrm{ATP}} \text { ) } \\
\text { ? Inhibit HDAC, leading to } \\
\text { increased resistance to oxidative } \\
\text { stress } \\
\text { ? Inhibit mitochondrial } \\
\text { permeability transition }\end{array}$ \\
\hline $\begin{array}{l}\text { Increased GABA synthesis (flux } \\
\text { through GAD) }\end{array}$ & $\begin{array}{l}\text { Brain converts ketone bodies to } \\
\text { acetyl-CoA; increased flux } \\
\text { through TCA cycle, consumes } \\
\text { oxaloacetate, which is less } \\
\text { available to the aspartate } \\
\text { aminotransferase reaction; less } \\
\text { glutamate is converted to } \\
\text { aspartate and relatively more } \\
\text { glutamate becomes available to } \\
\text { the glutamine synthetase and } \\
\text { GAD reactions }\end{array}$ & $\begin{array}{l}\text { ? Enhanced GABA-mediated } \\
\text { inhibition }\end{array}$ \\
\hline Adenosine & $\begin{array}{l}\text { Levels of ATP elevated leading to } \\
\text { increased conversion to } \\
\text { adenosine in neurons and } \\
\text { astrocytes }\end{array}$ & $\begin{array}{l}\text { Activation of adenosine A1 } \\
\text { receptors on excitatory neurons }\end{array}$ \\
\hline $\begin{array}{l}\text { Increased mitochondrial function } \\
\text { and biogenesis }\end{array}$ & Unknown & $\begin{array}{c}\text { Increase ATP production and } \\
\text { enhanced energy reserves }\end{array}$ \\
\hline Nrf2 & $\begin{array}{l}\text { Ketogenic diet initially produces } \\
\text { mild oxidative and electrophilic } \\
\text { stress, activating Nrf2 via redox } \\
\text { signaling }\end{array}$ & $\begin{array}{l}\text { Reversal of chronically low GSH in } \\
\text { epilepsy } \\
\text { Induction of genes encoding } \\
\text { protective proteins; } \\
\text { improvement of the } \\
\text { mitochondrial redox state }\end{array}$ \\
\hline Reduced mitochondrial ROS & $\begin{array}{l}\text { Enhanced expression of UCPs by } \\
\text { fatty acids acting on PPAR and } \\
\text { FOX }\end{array}$ & $\begin{array}{c}\text { Increased UCPs diminish } \Delta \Psi \\
\text { leading to reduced ROS }\end{array}$ \\
\hline Anaplerosis & $\begin{array}{l}\text { In ketogenic diet, there is reduction } \\
\text { in glycolysis and increase in } \\
\text { oxidation of FA and ketone } \\
\text { bodies (glycolytic restriction/ } \\
\text { diversion) }\end{array}$ & $\begin{array}{l}\text { Correct glutamate and GABA } \\
\text { deficiencies in brain } \\
\text { Enhanced neuronal ATP } \\
\text { production } \\
\text { Reduce expression of proepileptic } \\
\text { BDNF and TrkB through NRSF } \\
\text { binding to NRSE; decrease in } \\
\text { cytosolic and nuclear levels of } \\
\text { NADH }\end{array}$ \\
\hline
\end{tabular}


Table 2. Continued

\begin{tabular}{|c|c|c|}
\hline Mediator/physiological change & Basis & Mechanism of antiseizure effects \\
\hline PUFAs & $\begin{array}{l}\text { Ketogenic diet enhances } \\
\text { mobilization of PUFAs from } \\
\text { adipose tissue to liver and } \\
\text { brains }\end{array}$ & $\begin{array}{l}\text { PUFAs directly affect ion channels } \\
\text { Activation of PPAR } \alpha \text { and PGC-1 } \alpha \\
\text { (coactivator) leads to changes in } \\
\text { transcription of genes linked to } \\
\text { energy, amino acid, and } \\
\text { neurotransmitter metabolism } \\
\text { Boost activity of UCPs }\end{array}$ \\
\hline Medium-chain triglycerides & $\begin{array}{l}\text { Exogenous administration of in } \\
\text { the medium-chain triglyceride } \\
\text { ketogenic diet }\end{array}$ & $\begin{array}{l}\text { Unknown (similar action to } \\
\text { valproate) }\end{array}$ \\
\hline FFA3 & $\begin{array}{l}\text { Activated by short-chain fatty } \\
\text { acids and } \beta \text {-hydroxybutyrate }\end{array}$ & $\begin{array}{l}\text { Inhibit N-type voltage-gated } \\
\text { calcium channels, leading to } \\
\text { reduced glutamate release at } \\
\text { synapses }\end{array}$ \\
\hline
\end{tabular}

FFAs, Free fatty acids; HDAC, histone deacetylase; GABA, $\gamma$-aminobutyric acid; GAD, glutamic acid decarboxylase; Nrf2, NF E2-related factor 2; TCA, tricarboxylic acid; GSH, glutathione; ROS, reactive oxygen species; UCPs, uncoupling proteins; PPAR, peroxisome proliferator-activated receptor; FOX, forkhead box; FA, fatty acid; NRSF, neural restrictive silencing factor; NRSE, neuron restrictive silencing element; PUFAs, polyunsaturated fatty acids; BDNF, brain-derived neurotrophic factor; TrkB, tropomyosin receptor; $\mathrm{NADH}$, nicotinamide adenine dinucleotide (reduced).

along with the expected increases in acetyl-CoA, but there were no changes in the levels of GABA or glutamate (Yudkoff et al. 2005). The same study did show increases in glutamine and GABA on infusion of the nitrogen donors alanine or leucine. Rats fed the ketogenic diet for $3 \mathrm{wk}$ showed a reduction in brain glutamate levels, but also no change in GABA (Melo et al. 2006). However, in children fed the ketogenic diet, cerebrospinal fluid levels of GABA have been shown to increase, but without a change in glutamate concentrations (Dahlin et al. 2005). Another study in rats fed the ketogenic diet for $3 \mathrm{wk}$ found "increased" levels of glutamate and glutamine in the hippocampus (Bough et al. 2006). Further, using both mild caloric restriction ( $90 \%$ of daily energy requirements) and an isocaloric ketogenic diet, investigators found significant increases in the messenger RNA (mRNA) expression of both isoforms of GAD (GAD65 and GAD67) in several brain regions that were independent of ketogenic effects (Cheng et al. 2004); the functional implications are unclear given that GABA levels were not increased.

Recently, it has been proposed that the ketogenic diet could suppress neuronal excitabil- ity by inhibiting the presynaptic release of glutamate. The ketone bodies $\beta$-hydroxybutyrate and acetoacetate were shown to diminish glutamate release by directly competing with $\mathrm{Cl}^{-}$for allosteric activation of vesicular glutamate transporters (Juge et al. 2010). In the same study, application of the potassium channel blocker 4-aminopyridine to rat brain in vivo evoked seizures with concurrent secretion of glutamate, and these effects were blocked by acetoacetate. The relevance of this study is further supported by the recent observation that $\beta$-hydroxybutyrate does indeed induce antiseizure activity (Kim et al. 2015).

\section{$\mathrm{K}_{\mathrm{ATP}}$ Channels and GABA $A_{B}$ Receptors}

It has been proposed that activation of $\mathrm{K}_{\mathrm{ATP}}$ channels and $\mathrm{GABA}_{\mathrm{B}}$ receptors could underlie the action of the ketogenic diet (Ma et al. 2007). In brain slice recordings, acetoacetate and $\beta$-hydroxybutyrate were found to reduce the spontaneous firing rate of GABAergic neurons in the substantia nigra pars reticulata, a putative subcortical seizure gate, and this action was dependent on $\mathrm{K}_{\mathrm{ATP}}$ channels and $\mathrm{GABA}_{\mathrm{B}}$ receptors. Apart from the fact that $K_{A T P}$ channels and 
M.A. Rogawski et al.

$\mathrm{GABA}_{\mathrm{B}}$ receptors have been previously shown not to be germane antiseizure targets except in special circumstances (Meldrum and Rogawski 2007), most problematic for the hypothesis is the fact that the ketogenic diet and ketone bodies actually increase ATP production, which would tend to close $\mathrm{K}_{\mathrm{ATP}}$ channels and enhance instead of inhibit neuronal excitability (Masino and Rho 2012). In any case, the same group has shown that the open probability of $\mathrm{K}_{\mathrm{ATP}}$ channels in the hippocampus in vitro is enhanced in the presence of $\beta$-hydroxybutyrate (Tanner et al. 2011).

\section{Adenosine}

Recent studies have implicated the potent inhibitory modulator adenosine, which is well recognized to have antiseizure activity (Dunwiddie and Masino 2001), in the action of the ketogenic diet (Masino et al. 2012). Adenosine produces antiseizure effects through activation of inhibitory adenosine $A_{1}$ receptors on excitatory neurons. Adenosine is synthesized by hydrolysis of ATP in neurons and astrocytes. Because levels of ATP are elevated by the ketogenic diet, it is plausible that adenosine synthesis and release could also be enhanced. Targeted heterozygous $\left(A_{1} R^{+/-}\right)$or homozygous $\left(A_{1} R^{-/-}\right)$deletion of $\mathrm{A}_{1}$ receptors or increased expression of adenosine kinase $(A d k-T g)$, an enzyme that enhances clearance of adenosine, causes spontaneous electrographic seizures in mice (Masino et al. 2011). A 3-wk treatment with the ketogenic led to decreased electrographic seizures in $A d k-T g$ and $A_{1} R^{+/-}$mice, but not in animals entirely missing $\mathrm{A}_{1} \mathrm{R}$ receptors $\left(A_{1} R^{-/-}\right)$, supporting the concept that adenosine may be an important mediator of the ketogenic diet's antiseizure effects.

\section{Bioenergetic and Mitochondrial Changes}

Pathological changes in mitochondrial energy metabolism and reactive oxygen species (ROS) production are known to occur with epileptogenesis, and the ketogenic diet has been found to profoundly affect these processes (Rowley and Patel 2013). In addition to enhancing ener- gy reserves, ATP levels, and the expression of many enzymes involved in mitochondrial metabolism, the ketogenic diet has also been shown to increase mitochondrial biogenesis in the hippocampus (Bough et al. 2006) and to reduce oxidative stress through multiple cellular mechanisms, including those involving mitochondria, such as through increases in reduced glutathione (GSH). The effect on GSH is of particular interest because depletion of GSH is known to occur in epilepsy (Mueller et al. 2001). Increased GSH was shown to correlate with increased activity of glutamate cysteine ligase (GCL), the rate-limiting enzyme in GSH biosynthesis, and enhanced expression of the GCL catalytic subunit, GCLC, and modulatory subunit, GCLM, in rats fed the ketogenic diet (Jarrett et al. 2008).

The increase in GSH and associated changes were subsequently shown to involve NF E2related factor 2 (Nrf2), a redox-sensitive transcription factor that is activated by cellular stress and induces a diverse array of genes, including the GSH antioxidant pathway (Suzuki et al. 2013). The ketogenic diet resulted in elevated levels of Nrf2 for $3 \mathrm{wk}$, and this was associated with increased activity of $\mathrm{NAD}(\mathrm{P}) \mathrm{H}$ :quinone oxidoreductase, a prototypical Nrf2 target (Milder et al. 2010). Interestingly, a recent study found that increasing Nrf2 expression in a rat model of temporal lobe epilepsy decreased spontaneous seizures (Mazzuferi et al. 2013).

Acute application of the ketone bodies $\beta$ hydroxybutyrate and acetoacetate in hippocampal slices enhanced catalase activity in response $\mathrm{H}_{2} \mathrm{O}_{2}$ (Kim et al. 2010) and decreased oxidation of carboxy- $2^{\prime}, 7^{\prime}$-dichlorodihydrofluorescein diacetate, a dye often used as an indicator of intracellular ROS (Maalouf and Rho 2008). In isolated mitochondria, $\beta$-hydroxybutyrate and acetoacetate have been shown to decrease ROS levels in response to glutamate by enhancing oxidation of NADH (Maalouf et al. 2007). Additionally, $\beta$-hydroxybutyrate and acetoacetate reduced mitochondrial ROS both basally and in response to the ATP synthase inhibitor oligomycin (Kim et al. 2007).

A possible mechanism mediating the decrease in mitochondrial ROS production with 
the ketogenic diet is enhanced expression of uncoupling proteins (UCPs). Increased activity of UCPs can diminish the mitochondrial membrane potential $(\Delta \Psi)$, resulting in a decrease in ROS production, and this has been associated with increased resistance to kainate-induced seizures (Sullivan et al. 2003). Additionally, fatty acids can induce increases in UCP expression possibly through enhanced activity of transcription factors, such as the peroxisome proliferator-activated receptor (PPAR) and the forkhead box (FOX) family of transcription factors (Azzu and Brand 2010). In mice fed the ketogenic diet, UCP activity was enhanced and this was associated with increased levels of UCP2, UCP4, and UCP5 in the hippocampus (Sullivan et al. 2004). Additionally, ROS production-assessed in the presence of oligomycin to maximize $\Delta \Psi$-was reduced in mice fed the ketogenic diet (Sullivan et al. 2004).

Recently, $\beta$-hydroxybutyrate was shown to be an inhibitor of class I histone deacetylases (HDACs) in vitro and in vivo, and this activity was associated with increased resistance to oxidative stress (Shimazu et al. 2013). Specifically, $\beta$-hydroxybutyrate increased acetylation of histone $\mathrm{H} 3$ lysine 9 (H3K9) and histone $\mathrm{H} 3$ lysine 14 and enhanced transcription of genes regulated by FOXO3A, including the antioxidant enzymes manganese superoxide dismutase and catalase. Further, $\beta$-hydroxybutyrate (administered in vivo for $24 \mathrm{~h}$ via an osmotic pump) decreased protein carbonylation and 4-hydroxynonenal and lipid peroxides in the kidney. Although the investigators did not report such effects in neuronal tissue or cells, it is possible that direct inhibition of HDACs and the ensuing transcriptional changes may mediate some of the antioxidant effects known to occur in the brain with the ketogenic diet.

\section{Glycolytic Restriction/Diversion}

It has been proposed that increased neurotransmission caused by the hyperexcitability in neural networks in chronic epilepsy leads to depletion of TCA cycle intermediates, including $\alpha$-ketoglutarate, which is a precursor for glutamate and GABA (Borges and Sonnewald 2012).
Seizure susceptibility is further augmented by the reduction in these neurotransmitters and reduced energy (ATP) production as a result of diminished acetyl-CoA. A key feature of the ketogenic diet is a relative reduction in glycolysis and an increase in nonglucose sources of fuel through the oxidation of fatty acids and ketone bodies, which ultimately feed the TCA cycle through a process known as anaplerosis (i.e., the replenishing of depleted metabolic cycle intermediates). Anaplerosis is believed to correct the neurotransmitter (glutamate and GABA) deficiencies and enhance neuronal ATP production, which ultimately leads to a reduction in seizure susceptibility. Glycolytic restriction is thought to be an important mechanism mediating the antiseizure properties of the ketogenic diet (Masino and Rho 2012). Indeed, caloric restriction has antiseizure, and possibly antiepileptogenic, effects (Mantis et al. 2004). The earliest clinical observation supporting this notion is the rapid reversal of seizure control on ingestion of carbohydrates or glucose in patients on the ketogenic diet (Huttenlocher 1976). Additionally, studies in animals using labeled metabolic precursors have shown that the ketogenic diet reduces glycolysis (Yudkoff et al. 2005; Melo et al. 2006).

Recently, attempts have been made to mimic the antiseizure activity of the ketogenic diet using glycolytic inhibitors. In vitro application of 2-deoxy-D-glucose (2-DG), an inhibitor of phosphoglucose isomerase, reduced epileptiform bursts induced in hippocampal slices by bicuculline, 4-aminopyridine, and increased extracellular $\mathrm{K}^{+}$(Stafstrom et al. 2009). Additionally, in vivo administration of 2-DG provides protection against audiogenic and $6-\mathrm{Hz}$ stimulation-induced seizures in mice and also produced an antiseizure and antiepileptogenic effect in a rat kindling model (Garriga-Canut et al. 2006; Stafstrom et al. 2009; Gasior et al. 2010). The antiseizure effects of 2-DG may be partially mediated by changes in the expression of genes encoding brain-derived neurotrophic factor and its receptor TrkB, both of which are regulated by the activity of the transcription factor neural restrictive silencing factor (NRSF), which represses transcription by binding to the 
M.A. Rogawski et al.

neuron restrictive silencing element (NRSE) in promoter regions (Garriga-Canut et al. 2006). NRSF transcriptional repression was enhanced by 2-DG and this was associated with a reduction in acetylation and an increase in methylation of $\mathrm{H} 3 \mathrm{~K} 9$ at the NRSE promoter, epigenetic modifications associated with suppression of gene transcription. NRSF-mediated repression required an interaction with the transcriptional corepressor carboxyl-terminal binding protein that was disrupted with increasing concentrations of $\mathrm{NADH}$, a cofactor that is elevated on increased glycolytic flux. This suggests that the antiseizure actions of 2-DG may be mediated by a decrease in cytosolic and nuclear levels of $\mathrm{NADH}$ and subsequent influences on histone modifications.

Fructose-1,6-bisphosphate (FBP) also inhibits glycolysis by diverting the metabolism of glucose to the pentose phosphate pathway and affords antiseizure effects in vivo. FBP was found to protect against pilocarpine, kainate, and PTZ-induced seizures in rats (Lian et al. 2007) and also affected kindling acquisition (Ding et al. 2010). FBP had broader activity than valproate and 2-DG, whereas the ketogenic diet was not active in the models. These results reinforce the view that diversion of metabolism away from glycolysis is a promising antiseizure strategy.

Triheptanoin, the triglyceride of the C7 fatty acid heptanoate, is an anaplerotic substrate that restores levels of TCA intermediates (Hadera et al. 2014). Oral administration of triheptanoin has been shown to have antiseizure effects in some animal models, providing support for the anaplerosis hypothesis (Willis et al. 2010; Kim et al. 2013). A recent report suggests that triheptanoin may also have anti-ictal activity in humans (Pascual et al. 2014).

\section{Fatty Acid Oxidation and Polyunsaturated Fatty Acids}

Intake of a high-fat diet, such as the ketogenic diet, increases the rate of fatty acid oxidation. This leads to changes in the levels and types of polyunsaturated fatty acids (PUFAs) in the circulation, liver, and brain. In particular, it has been show that there is enhanced mobilization of PUFAs from adipose tissue to liver and brain (Taha et al. 2005). Large quantities of PUFAs are not a typical component of the ketogenic diet, thus increases in PUFAs must be the result of endogenous production and export into the circulation (Fraser et al. 2003). PUFAs affect diverse ion channels, including voltage-gated sodium and potassium channels (Vreugdenhil et al. 1996), and it has been speculated that actions of PUFAs on such ion channels could mediate the antiseizure effects of the ketogenic diet (Michael-Titus and Priestley 2013). An additional mechanism whereby PUFAs could affect seizure susceptibility is through activation of peroxisome proliferator-activated receptor- $\alpha$ $(\operatorname{PPAR} \alpha)$, a nuclear receptor that regulates the transcription of numerous genes linked to energy, amino acid, and neurotransmitter metabolism. Recently, it was shown that fenofibrate, a PPAR $\alpha$ ligand, exerts anticonvulsant activity comparable to the ketogenic diet in adult rats (Porta et al. 2009). The specific genes relevant to this effect remain to be determined.

In pediatric patients with epilepsy, 3-4 wk of ketogenic diet treatment led to elevations in circulating levels of $\beta$-hydroxybutyrate, cortisol, and free fatty acids (FFAs) (Fraser et al. 2003). Most PUFAs were also increased in the serum, including the triglyceride and phospholipid forms of linoleic acid (LA), arachidonic acid (AA) and docosahexaenoic acid (DHA), triglyceride levels of stearic acid, and palmitic acid in phospholipids. Additionally, these alterations in fatty acids were associated with seizure reduction in $78 \%$ of the children. Interestingly, seizure control was correlated with circulating AA levels, but not EEG changes.

Whether PUFA ingestion can render antiseizure effects remains controversial. Oral supplementation with $5 \mathrm{~g}$ of omega-3 PUFA for 6 mo appeared to reduce the frequency and severity of seizures in a small observational study (Schlanger et al. 2002). However, in a 12-wk randomized, placebo-controlled parallel group study in adults with epilepsy, administration of eicosapentaenoic acid (EPA) and DHA (1 g EPA, $0.7 \mathrm{~g}$ DHA daily) reduced seizure frequency for the first 6 wk of treatment, but this effect did not persist in spite of sustained increases in 
DHA and EPA and decreases in AA and LA in the plasma (Yuen et al. 2005). In an additional randomized, blinded trial of PUFA supplementation (EPA plus DHA, $2.2 \mathrm{mg} / \mathrm{d}$ in a $3: 2$ ratio over $12 \mathrm{wk}$ ) in adults with uncontrolled epilepsy, there was a lack of clear efficacy when compared with placebo (Bromfield et al. 2008).

In rats fed the ketogenic diet, there were marked reductions of PUFA levels in plasma and adipose tissue, but enhanced mobilization of the PUFA AA and DHA to the liver and brain (Taha et al. 2005). This was accompanied by an initial increase in plasma levels of $\beta$-hydroxybutyrate, followed by a reduction by day 10 of the diet. Following a calorie-restricted ketogenic diet, mRNA expression of the ratelimiting enzyme for ketone body production, HMG-CoAS2, was found to increase in both the liver and brain, in contrast to feeding with an isocaloric standard chow, which resulted in enhanced expression only in the liver (Cullingford et al. 2002). Collectively, these and other animal studies suggest that diet-induced changes in brain content and metabolism of PUFAs may be important contributors to antiseizure effects of the ketogenic diet (Taha et al. 2010).

\section{Medium-Chain Triglycerides}

The medium-chain triglyceride ketogenic diet is as efficacious as the classic ketogenic diet in which the primary fat source is long-chain triglycerides (Huttenlocher et al. 1971; Neal et al. 2009; Liu and Wang 2013). This diet increases the plasma levels of medium straight-chain fatty acids. Recently, medium-chain triglycerides of various structural classes have been shown to reduce the frequency of epileptiform discharges in in vitro slice models and to inhibit behavioral and EEG seizures in a rat status epilepticus model; modest activity was also reported in various in vivo models used to screen for antiseizure activity (Chang et al. 2012, 2013, 2015). Valproate is a short-branched-chain fatty acid. Certain structurally novel medium-chain fatty acids have been identified that have greater activity than valproate in seizure models and that lack the HDAC activity of valproate, which has been proposed as a basis for its teratogenicity.
Whether administration of a specific mediumchain triglyceride in the presence of a normal diet could represent an epilepsy treatment approach remains to be determined.

\section{Free Fatty Acid Receptor 3}

Free fatty acid receptor 3 (FFA3) is a G-protein coupled receptor whose endogenous ligands may include short-chain fatty acids, such as acetate and propionate. A study in dissociated sympathetic neurons recently showed that $\beta$ hydroxybutyrate is also an agonist of FFA3, causing inhibition of $\mathrm{N}$-type voltage-gated calcium channels (Won et al. 2013). A prior study also found the ketone body to interact with FFA3, but in this case it was an antagonist (Kimura et al. 2011); the basis for the discrepancy is not apparent. As of yet, the relevance of these actions to brain function remains to be determined.

\section{CONCLUSION}

In recent years, there have been dramatic advances in our understanding of how ASDs prevent seizures. ASDs interact with a wide variety of molecular targets. There are unique aspects to the mechanism of each ASD so that it is rarely the case that two ASDs have what could be considered the same mechanisms of action (gabapentin and pregabalin are perhaps exceptions). Although some ASDs have a single cognate target, for many of the drugs, clinical activity is likely the result of actions on several targets. This makes the definition of "mechanism of action" challenging, but it is perhaps not surprising that control of epilepsy, which is a functional disorder of neural networks, would benefit from therapeutic interventions at various points in the network.

Although ASDs provide control of seizures for many people with epilepsy, a disappointingly large number do not achieve seizure freedom with medications. The ketogenic diet is an alternative approach that may provide seizure control in cases of drug-resistant epilepsy. There are still many open questions regarding the mechanisms of the ketogenic diet. However, as 
M.A. Rogawski et al.

reviewed here, effects of the diet on intermediary metabolism are likely to be central to its therapeutic activity. These mechanisms are fundamentally different from those believed to be relevant to ASDs. Consequently, study of the ketogenic diet may open avenues to the creation of entirely novel treatment strategies for pharmacoresistant epilepsies. Such treatment approaches may improve on the efficacy of the diet and be more convenient and palatable. There is, therefore, strong justification for continued investigation of ketogenic diet mechanisms.

\section{ACKNOWLEDGMENTS}

M.A.R.'s research is supported by the National Institute of Neurological Disorders and Stroke (NS079202). J.M.R.'s research is supported by the Canadian Institutes of Health Research.

\section{REFERENCES}

Ahmed GF, Marino SE, Brundage RC, Pakhomov SV, Leppik IE, Cloyd JC, Clark A, Birnbaum AK. 2015. Pharmacokinetic-pharmacodynamic modelling of intravenous and oral topiramate and its effect on phonemic fluency in adult healthy volunteers. BrJClin Pharmacol 79:820-830.

Alexander SPH, Benson HE, Faccenda E, Pawson AJ, Sharman JL, Catterall WA, Spedding M, Peters JA, Harmar AJ; CGTP Collaborators. 2013. The concise guide to PHARMACOLOGY 2013/14: Ion channels. Br J Pharmacol 170: $1607-1651$

Avoli M, Kawasaki H, Zona C. 1996. Effects induced by topiramate on sodium electrogenesis in mammalian central neurons. Epilepsia 37: 51-52.

Avoli M, Rogawski MA, Avanzini G. 2001. Generalized epileptic disorders: An update. Epilepsia 42: 445-457.

Azzu V, Brand MD. 2010. The on-off switches of the mitochondrial uncoupling proteins. Trends Biochem Sci 35: 298-307.

Berg AT, Levy SR, Testa FM, Blumenfeld H. 2014. Long-term seizure remission in childhood absence epilepsy: Might initial treatment matter? Epilepsia 55: 551-557.

Biton V. 2007. Clinical pharmacology and mechanism of action of zonisamide. Clin Neuropharmacol 30: 230-240.

Blumenfeld H, Klein JP, Schridde U, Vestal M, Rice T, Khera DS, Bashyal C, Giblin K, Paul-Laughinghouse C, Wang F et al. 2008. Early treatment suppresses the development of spike-wave epilepsy in a rat model. Epilepsia 49: 400409.

Blumenfeld H, Varghese GI, Purcaro MJ, Motelow JE, Enev M, McNally KA, Levin AR, Hirsch LJ, Tikofsky R, Zubal IG, et al. 2009. Cortical and subcortical networks in hu- man secondarily generalized tonic-clonic seizures. Brain 132: 999-1012.

Borges K, Sonnewald U. 2012. Triheptanoin-A medium chain triglyceride with odd chain fatty acids: A new anaplerotic anticonvulsant treatment? Epilepsy Res 100: 239-244.

Bough KJ, Wetherington J, Hassel B, Pare JF, Gawryluk JW, Greene JG, Shaw R, Smith Y, Geiger JD, Dingledine RJ. 2006. Mitochondrial biogenesis in the anticonvulsant mechanism of the ketogenic diet. Ann Neurol 60: $223-$ 235.

Broicher T, Seidenbecher T, Meuth P, Munsch T, Meuth SG, Kanyshkova T, Pape HC, Budde T. 2007. T-current related effects of antiepileptic drugs and a $\mathrm{Ca}^{2+}$ channel antagonist on thalamic relay and local circuit interneurons in a rat model of absence epilepsy. Neuropharmacology $\mathbf{5 3}$ 431-446.

Bromfield E, Dworetzky B, Hurwitz S, Eluri Z, Lane L, Replansky S, Mostofsky D. 2008. A randomized trial of polyunsaturated fatty acids for refractory epilepsy. Epilepsy Behav 12: 187-190.

Brown DA, Passmore GM. 2009. Neural KCNQ (Kv7) channels. Br J Pharmacol 156: 1185-1195.

Chang P, Orabi B, Deranieh RM, Dham M, Hoeller O, Shimshoni JA, Yagen B, Bialer M, Greenberg ML, Walker MC, et al. 2012. The antiepileptic drug valproic acid and other medium-chain fatty acids acutely reduce phosphoinositide levels independently of inositol in Dictyostelium. Dis Model Mech 5: 115-124.

Chang P, Terbach N, Plant N, Chen PE, Walker MC, Williams RS. 2013. Seizure control by ketogenic diet-associated medium chain fatty acids. Neuropharmacology 69: $105-114$.

Chang P, Zuckermann AM, Williams S, Close AJ, CanoJaimez M, McEvoy JP, Spencer J, Walker MC, Williams RS. 2015. Seizure control by derivatives of medium chain fatty acids associated with the ketogenic diet show novel branching-point structure for enhanced potency. J Pharmacol Exp Ther 352: 43-52.

Charlier C, Singh NA, Ryan SG, Lewis TB, Reus BE, Leach RJ, Leppert M. 1998. A pore mutation in a novel KQT-like potassium channel gene in an idiopathic epilepsy family. Nat Genet 18: 53-55.

Chen CY, Matt L, Hell JW, Rogawski MA. 2014. Perampanel inhibition of AMPA receptor currents in cultured hippocampal neurons. PLoS ONE 9: e108021.

Cheng CM, Wang K, Eagles DA, Bondy CA. 2004. Caloric restriction augments brain glutamic acid decarboxylase65 and -67 expression. J Neurosci Res 77: 270-276.

Cooper EC. 2012. Potassium channels (including KCNQ) and epilepsy. In Jasper's basic mechanisms of the epilepsies, 4 th ed. (ed. Noebels JL, et al.), pp. 55-65. Oxford University Press, New York.

Coulter DA, Huguenard JR, Prince DA. 1989. Characterization of ethosuximide reduction of low-threshold calcium current in thalamic relay neurons. Ann Neurol 25: 582 593.

Crunelli V, David F, Leresche N, Lambert RC. 2014. Role for T-type $\mathrm{Ca}^{2+}$ channels in sleep waves. Pflugers Arch 466: $735-745$. 
Cullingford TE, Eagles DA, Sato H. 2002. The ketogenic diet upregulates expression of the gene encoding the key ketogenic enzyme mitochondrial 3-hydroxy-3-methylglutaryl-CoA synthase in rat brain. Epilepsy Res 49: 99-107.

Dahlin M, Elfving A, Ungerstedt U, Amark P. 2005. The ketogenic diet influences the levels of excitatory and inhibitory amino acids in the CSF in children with refractory epilepsy. Epilepsy Res 64: 115-125.

Danober L, Deransart C, Depaulis A, Vergnes M, Marescaux C. 1998. Pathophysiological mechanisms of genetic absence epilepsy in the rat. Prog Neurobiol 55: 27-57.

Davies A, Hendrich J, Van Minh AT, Wratten J, Douglas L, Dolphin AC. 2007. Functional biology of the $\alpha_{2} \delta$ subunits of voltage-gated calcium channels. Trends Pharmacol Sci 28: 220-228.

Deckers CL, Czuczwar SJ, Hekster YA, Keyser A, Kubova H, Meinardi H, Patsalos PN, Renier WO, Van Rijn CM. 2000. Selection of antiepileptic drug polytherapy based on mechanisms of action: The evidence reviewed. Epilepsia 41: 1364-1374.

Dezsi G, Ozturk E, Stanic D, Powell KL, Blumenfeld H, O’Brien TJ, Jones NC. 2013. Ethosuximide reduces epileptogenesis and behavioral comorbidity in the GAERS model of genetic generalized epilepsy. Epilepsia 54: 635-643.

Ding Y, Wang S, Zhang MM, Guo Y, Yang Y, Weng SQ, Wu JM, Qiu X, Ding MP. 2010. Fructose-1,6-diphosphate inhibits seizure acquisition in fast hippocampal kindling. Neurosci Lett 477: 33-36.

Dodgson SJ, Shank RP, Maryanoff BE. 2000. Topiramate as an inhibitor of carbonic anhydrase isoenzymes. Epilepsia 41: S35-S39.

Dolphin AC. 2013. The $\alpha_{2} \delta$ subunits of voltage-gated calcium channels. Biochim Biophys Acta 1828: 1541-1549.

Dunwiddie TV, Masino SA. 2001. The role and regulation of adenosine in the central nervous system. Annu Rev Neurosci 24: 31-55.

Eid T, Kovacs I, Spencer DD, de Lanerolle NC. 2002. Novel expression of AMPA-receptor subunit GluR1 on mossy cells and CA3 pyramidal neurons in the human epileptogenic hippocampus. Eur J Neurosci 15: 517-527.

Englund M, Hyllienmark L, Brismar T. 2011. Effect of valproate, lamotrigine and levetiracetam on excitability and firing properties of CA1 neurons in rat brain slices. Cell Mol Neurobiol 31: 645-652.

ffrench-Mullen JM, Barker JL, Rogawski MA. 1993. Calcium current block by (-)-pentobarbital, phenobarbital, and CHEB but not $(+)$-pentobarbital in acutely isolated hippocampal CA1 neurons: Comparison with effects on GABA-activated $\mathrm{Cl}^{-}$current. J Neurosci 13: 3211-3221.

Field MJ, Cox PJ, Stott E, Melrose H, Offord J, Su TZ, Bramwell S, Corradini L, England S, Winks J, et al. 2006. Identification of the $\alpha_{2}-\delta-1$ subunit of voltagedependent calcium channels as a molecular target for pain mediating the analgesic actions of pregabalin. Proc Natl Acad Sci 103: 17537-17542.

Frahm C, Engel D, Draguhn A. 2001. Efficacy of background GABA uptake in rat hippocampal slices. NeuroReport 12: 1593-1596.

Fraser DD, Whiting S, Andrew RD, Macdonald EA, MusaVeloso K, Cunnane SC. 2003. Elevated polyunsaturated fatty acids in blood serum obtained from children on the ketogenic diet. Neurology 60: 1026-1029.

Freeman JM, Kossoff EH. 2010. Ketosis and the ketogenic diet, 2010: Advances in treating epilepsy and other disorders. Adv Pediatr 57: 315-329.

Fritsch B, Reis J, Gasior M, Kaminski RM, Rogawski MA. 2014. Role of GluK1 kainate receptors in seizures, epileptic discharges, and epileptogenesis. J Neurosci 34: 57655775.

García-Pérez E, Lo DC, Wesseling JF. 2008. Kinetic isolation of a slowly recovering component of short-term depression during exhaustive use at excitatory hippocampal synapses. J Neurophysiol 100: 781-795.

García-Pérez E, Mahfooz K, Covita J, Zandueta A, Wesseling JF. 2015. Levetiracetam accelerates the onset of supply rate depression in synaptic vesicle trafficking. Epilepsia 56: 535-545.

Garriga-Canut M, Schoenike B, Qazi R, Bergendahl K, Daley TJ, Pfender RM, Morrison JF, Ockuly J, Stafstrom C, Sutula T, et al. 2006. 2-Deoxy-D-glucose reduces epilepsy progression by NRSF-CtBP-dependent metabolic regulation of chromatin structure. Nat Neurosci 9: 1382-1387.

Gasior M, Rogawski MA, Hartman AL. 2006. Neuroprotective and disease-modifying effects of the ketogenic diet. Behav Pharmacol 17: 431-439.

Gasior M, French A, Joy MT, Tang RS, Hartman AL, Rogawski MA. 2007. The anticonvulsant activity of acetone, the major ketone body in the ketogenic diet, is not dependent on its metabolites acetol, 1,2-propanediol, methylglyoxal, or pyruvic acid. Epilepsia 48: 793-800.

Gasior M, Yankura J, Hartman AL, French A, Rogawski MA. 2010. Anticonvulsant and proconvulsant actions of 2-deoxy-D-glucose. Epilepsia 51: 1385-1394.

Gibbs JW 3rd, Sombati S, DeLorenzo RJ, Coulter DA. 2000. Cellular actions of topiramate: Blockade of kainate-evoked inward currents in cultured hippocampal neurons. Epilepsia 41: S10-S16.

Gilchrist J, Dutton S, Diaz-Bustamante M, McPherson A, Olivares N, Kalia J, Escayg A, Bosmans F. 2014. $\mathrm{Na}_{\mathrm{v}} 1.1$ modulation by a novel triazole compound attenuates epileptic seizures in rodents. ACS Chem Biol 9: 1204-1212.

Gomora JC, Daud AN, Weiergräber M, Perez-Reyes E. 2001. Block of cloned human T-type calcium channels by succinimide antiepileptic drugs. Mol Pharmacol 60: 11211132.

Gören MZ, Onat F. 2007. Ethosuximide: From bench to bedside. CNS Drug Rev 13: 224-239.

Grigorov A, Moskalyuk A, Kravchenko M, Veselovsky N, Verkhratsky A, Fedulova S. 2014. $\mathrm{K}_{\mathrm{v}} 7$ potassium channel subunits and $\mathrm{M}$ currents in cultured hippocampal interneurons. Pflugers Arch 466:1747-1758.

Grunnet M, Strøbæk D, Hougaard C, Christophersen P. 2014. $\mathrm{K}_{\mathrm{v}} 7$ channels as targets for anti-epileptic and psychiatric drug-development. Eur J Pharmacol 726: $133-$ 137.

Gu N, Vervaeke K, Hu H, Storm JF. 2005. K $7 /$ KCNQ/M and $\mathrm{HCN} / \mathrm{h}$, but not $\mathrm{K}_{\mathrm{Ca}} 2 / \mathrm{SK}$ channels, contribute to the somatic medium after-hyperpolarization and excitability control in CA1 hippocampal pyramidal cells. $J$ Physiol 566: 689-715. 
M.A. Rogawski et al.

Gunthorpe MJ, Large CH, Sankar R. 2012. The mechanism of action of retigabine (ezogabine), a first-in-class $\mathrm{K}^{+}$ channel opener for the treatment of epilepsy. Epilepsia 53: $412-424$.

Hadera MG, Smeland OB, McDonald TS, Tan KN, Sonnewald U, Borges K. 2014. Triheptanoin partially restores levels of tricarboxylic acid cycle intermediates in the mouse pilocarpine model of epilepsy. J Neurochem 129: 107-119.

Hanada T, Hashizume Y, Tokuhara N, Takenaka O, Kohmura N, Ogasawara A, Hatakeyama S, Ohgoh M, Ueno M, Nishizawa Y. 2011. Perampanel: A novel, orally active, noncompetitive AMPA-receptor antagonist that reduces seizure activity in rodent models of epilepsy. Epilepsia 52: 1331-1340.

Hassel B, Dingledine R. 2012. Glutamate and glutamate receptors. In Basic neurochemistry: Principles of molecular, cellular, and medical neurobiology, 8th ed. (ed. Scott T, Brady ST, Siegel GJ, et al.), pp. 343-366. Elsevier, Amsterdam.

Hermann R, Ferron GM, Erb K, Knebel N, Ruus P, Paul J, Richards L, Cnota HP, Troy S. 2003. Effects of age and sex on the disposition of retigabine. Clin Pharmacol Ther 73: $61-70$.

Hoppa MB, Lana B, Margas W, Dolphin AC, Ryan TA. 2012. $\alpha_{2} \delta$ Expression sets presynaptic calcium channel abundance and release probability. Nature 486: 122-125.

Houser CR. 2014. Do structural changes in GABA neurons give rise to the epileptic state? Adv Exp Med Biol 813: 151-160.

Hu H, Vervaeke K, Storm JF. 2007. M-channels (K $7 /$ KCNQ channels) that regulate synaptic integration, excitability, and spike pattern of CA1 pyramidal cells are located in the perisomatic region. J Neurosci 27: 1853-1867.

Huang CW, Kuo CC. 2015. Flow- and voltage-dependent blocking effect of ethosuximide on the inward rectifier $\mathrm{K}^{+}$(Kir2.1) channel. Pflugers Arch 467: 1733-1746.

Hughes JR. 2009. Absence seizures: A review of recent reports with new concepts. Epilepsy Behav 15: 404-412.

Huguenard JR. 1996. Low-threshold calcium currents in central nervous system neurons. Annu Rev Physiol 58: 329-358.

Huguenard JR. 2002. Block of T-type $\mathrm{Ca}^{2+}$ channels is an important action of succinimide antiabsence drugs. Epilepsy Curr 2: 49-52.

Huttenlocher PR. 1976. Ketonemia and seizures: Metabolic and anticonvulsant effects of two ketogenic diets in childhood epilepsy. Pediatr Res 10: 536-540.

Huttenlocher PR, Wilbourn AJ, Signore JM. 1971. Mediumchain triglycerides as a therapy for intractable childhood epilepsy. Neurology 21: 1097-1103.

Jarrett SG, Milder JB, Liang LP, Patel M. 2008. The ketogenic diet increases mitochondrial glutathione levels. J Neurochem 106: 1044-1051.

Juge N, Gray JA, Omote H, Miyaji T, Inoue T, Hara C, Uneyama H, Edwards RH, Nicoll RA, Moriyama Y. 2010. Metabolic control of vesicular glutamate transport and release. Neuron 68: 99-112.

Kaminski RM, Gillard M, Klitgaard H. 2012. Targeting SV2A for discovery of antiepileptic drugs. In Jasper's basic mechanisms of the epilepsies, 4th ed. (ed. Noebels JL, et al.), pp. 974-983. Oxford University Press, New York.

Kaminski RM, Rogawski MA, Klitgaard H. 2014. The potential of antiseizure drugs and agents that act on novel molecular targets as antiepileptogenic treatments. Neurotherapeutics 11: 385-400.

Kapetanovic IM, Yonekawa WD, Kupferberg HJ. 1995. The effects of D-23129, a new experimental anticonvulsant drug, on neurotransmitter amino acids in the rat hippocampus in vitro. Epilepsy Res 22: 167-173.

Kasteleijn-Nolst Trenité D, Brandt C, Mayer T, Rosenow F, Schmidt B, Steinhoff BJ, Gardin A, Imbert G, Johns D, Sagkriotis A, et al. 2015. Dose-dependent suppression of human photoparoxysmal response with the competitive AMPA/kainate receptor antagonist BGG492: Clear PK/ PD relationship. Epilepsia 56: 924-932.

Keith HM. 1933. Factors influencing experimentally produced convulsions. Arch Neurol Psychiatry 29: 148-154.

Kim DY, Davis LM, Sullivan PG, Maalouf M, Simeone TA, van Brederode J, Rho JM. 2007. Ketone bodies are protective against oxidative stress in neocortical neurons. $J$ Neurochem 101: 1316-1326.

Kim DY, Vallejo J, Rho JM. 2010. Ketones prevent synaptic dysfunction induced by mitochondrial respiratory complex inhibitors. J Neurochem 114: 130-141.

Kim TH, Borges K, Petrou S, Reid CA. 2013. Triheptanoin reduces seizure susceptibility in a syndrome-specific mouse model of generalized epilepsy. Epilepsy Res 103: 101-105.

Kim DY, Simeone KA, Simeone TA, Pandya JD, Wilke JC, Ahn Y, Geddes JW, Sullivan PG, Rho JM. 2015. Ketone bodies mediate antiseizure effects through mitochondrial permeability transition. Ann Neurol 78: 77-87.

Kimura I, Inoue D, Maeda T, Hara T, Ichimura A, Miyauchi S, Kobayashi M, Hirasawa A, Tsujimoto G. Short-chain fatty acids and ketones directly regulate sympathetic nervous system via G protein-coupled receptor 41 (GPR41). 2011. Proc Natl Acad Sci 108: 8030-8035.

Lambert RC, Bessaïh T, Crunelli V, Leresche N. 2014. The many faces of T-type calcium channels. Pflugers Arch 466: $415-423$.

Lawrence JJ, Saraga F, Churchill JF, Statland JM, Travis KE, Skinner FK, McBain CJ. 2006. Somatodendritic $\mathrm{K}_{\mathrm{v}} 7$ / $\mathrm{KCNQ} / \mathrm{M}$ channels control interspike interval in hippocampal interneurons. J Neurosci 26: 12325-12338.

Lennox WG, Cobb S. 1928. Epilepsy: From the standpoint of physiology and treatment. Medicine 7: 105-290.

Leppik IE, Sherwin AL. 1977. Anticonvulsant activity of phenobarbital and phenytoin in combination. J Pharmacol Exp Ther 200: 570-575.

Li G, Nowak M, Bauer S, Schlegel K, Stei S, Allenhöfer L, Waschbisch A, Tackenberg B, Höllerhage M, Höglinger GU, et al. 2013. Levetiracetam but not valproate inhibits function of $\mathrm{CD}^{+} \mathrm{T}$ lymphocytes. Seizure 22: 462-466.

Lian XY, Khan FA, Stringer JL. 2007. Fructose-1,6-bisphosphate has anticonvulsant activity in models of acute seizures in adult rats. J Neurosci 27: 12007-12011.

Likhodii SS, Serbanescu I, Cortez MA, Murphy P, Snead OC III, Burnham WM. 2003. Anticonvulsant properties of acetone, a brain ketone elevated by the ketogenic diet. Ann Neurol 54: 219-226. 
Liu YM, Wang HS. 2013. Medium-chain triglyceride ketogenic diet, an effective treatment for drug-resistant epilepsy and a comparison with other ketogenic diets. Biomed J 36: 9-15.

Löscher W. 1989. Valproate enhances GABA turnover in the substantia nigra. Brain Res 501: 198-203.

Löscher W. 1998. Pharmacology of glutamate receptor antagonists in the kindling model. In Kindling 5 (ed. Corcoran ME, Moshé SL), pp. 435-449. Plenum, New York.

Löscher W. 2002. Basic pharmacology of valproate: A review after 35 years of clinical use for the treatment of epilepsy. CNS Drugs 16: 669-694.

Löscher W, Rogawski MA. 2012. How theories evolved concerning the mechanism of action of barbiturates. Epilepsia 53: $12-25$.

Löscher W, Jäckel R, Müller F. 1989. Anticonvulsant and proconvulsant effects of inhibitors of GABA degradation in the amygdala-kindling model. Eur J Pharmacol 163: $1-14$.

Löscher W, Hönack D, Taylor CP. 1991. Gabapentin increases aminooxyacetic acid-induced GABA accumulation in several regions of rat brain. Neurosci Lett 128: 150-154.

Löscher W, Hönack D, Bloms-Funke P. 1996. The nove antiepileptic drug levetiracetam (ucb L059) induces alterations in GABA metabolism and turnover in discrete areas of rat brain and reduces neuronal activity in substantia nigra pars reticulata. Brain Res 735: 208-216.

Lotarski SM, Donevan S, El-Kattan A, Osgood S, Poe J, Taylor CP, Offord J. 2011. Anxiolytic-like activity of pregabalin in the Vogel conflict test in $\alpha_{2} \delta-1$ (R217A) and $\alpha_{2} \delta-2$ (R279A) mouse mutants. J Pharmacol Exp Ther 338: 615-621.

Lynch BA, Matagne A, Brännström A, von Euler A, Jansson M, Hauzenberger E, Söderhäll JA. 2008. Visualization of SV2A conformations in situ by the use of protein tomography. Biochem Biophys Res Commun 375: 491-495.

Lyseng-Williamson KA. 2011. Spotlight on levetiracetam in epilepsy. CNS Drugs 25: 901-905.

Ma W, Berg J, Yellen G. 2007. Ketogenic diet metabolites reduce firing in central neurons by opening $\mathrm{K}_{\mathrm{ATP}}$ channels. J Neurosci 27: 3618-3625.

Maalouf M, Rho JM. 2008. Oxidative impairment of hippocampal long-term potentiation involves activation of protein phosphatase $2 \mathrm{~A}$ and is prevented by ketone bodies. J Neurosci Res 86: 3322-3330.

Maalouf M, Sullivan PG, Davis L, Kim DY, Rho JM. 2007. Ketones inhibit mitochondrial production of reactive oxygen species production following glutamate excitotoxicity by increasing NADH oxidation. Neuroscience 145: 256-264.

Mantegazza M, Curia G, Biagini G, Ragsdale DS, Avoli M. 2010. Voltage-gated sodium channels as therapeutic targets in epilepsy and other neurological disorders. Lancet Neurol 9: 413-424.

Mantis JG, Centeno NA, Todorova MT, McGowan R, Seyfried TN. 2004. Management of multifactorial idiopathic epilepsy in EL mice with caloric restriction and the ketogenic diet: Role of glucose and ketone bodies. Nutr Metab (Lond) 1: 11.

Margolis JM, Chu BC, Wang ZJ, Copher R, Cavazos JE. 2014. Effectiveness of antiepileptic drug combination therapy for partial-onset seizures based on mechanisms of action. JAMA Neurol 71: 985-993.

Martire M, Castaldo P, D’Amico M, Preziosi P, Annunziato L, Taglialatela M. 2004. M channels containing KCNQ2 subunits modulate norepinephrine, aspartate, and GABA release from hippocampal nerve terminals. $J$ Neurosci 24: 592-597.

Masino SA, Rho JM. 2012. Mechanisms of ketogenic diet action. In Jasper's basic mechanisms of the epilepsies, 4th ed. (ed. Noebels JL, et al.), pp. 1003-1024. Oxford University Press, New York.

Masino SA, Li T, Theofilas P, Sandau US, Ruskin DN, Fredholm BB, Geiger JD, Aronica E, Boison D. 2011. A ketogenic diet suppresses seizures in mice through adenosine $\mathrm{A}_{1}$ receptors. J Clin Invest 121: 2679-2683.

Masino SA, Kawamura M Jr, Ruskin DN, Geiger JD, Boison D. 2012. Purines and neuronal excitability: Links to the ketogenic diet. Epilepsy Res 100: 229-238.

Matar N, Jin W, Wrubel H, Hescheler J, Schneider T, Weiergräber M. 2009. Zonisamide block of cloned human T-type voltage-gated calcium channels. Epilepsy Res 83: 224-234.

Mathern GW, Pretorius JK, Mendoza D, Lozada A, Leite JP, Chimelli L, Fried I, Sakamoto AC, Assirati JA, Adelson PD. 1998. Increased hippocampal AMPA and NMDA receptor subunit immunoreactivity in temporal lobe epilepsy patients. J Neuropathol Exp Neurol 57: 615-634.

Mazzuferi M, Kumar G, van Eyll J, Danis B, Foerch P, Kaminski RM. 2013. Nrf2 defense pathway: Experimental evidence for its protective role in epilepsy. Ann Neurol 74: $560-568$.

Medina-Kauwe LK, Tobin AJ, De Meirleir L, Jaeken J, Jakobs C, Nyhan WL, Gibson KM. 1999. 4-Aminobutyrate aminotransferase (GABA-transaminase) deficiency. J Inherit Metab Dis 22: 414-427.

Meehan AL, Yang X, McAdams BD, Yuan L, Rothman SM. 2011. A new mechanism for antiepileptic drug action: Vesicular entry may mediate the effects of levetiracetam. J Neurophysiol 106: 1227-1239.

Meehan AL, Yang X, Yuan LL, Rothman SM. 2012. Levetiracetam has an activity-dependent effect on inhibitory transmission. Epilepsia 53: 469-476.

Meldrum BS, Rogawski MA. 2007. Molecular targets for antiepileptic drug development. Neurotherapeutics 4: $18-61$.

Melo TM, Nehlig A, Sonnewald U. 2006. Neuronal-glial interactions in rats fed a ketogenic diet. Neurochem Int 48: 498-507.

Michael-Titus AT, Priestley JV. 2013. Omega-3 fatty acids and traumatic neurological injury: From neuroprotection to neuroplasticity? Trends Neurosci 37: 30-38.

Milder JB, Liang LP, Patel M. 2010. Acute oxidative stress and systemic Nrf2 activation by the ketogenic diet. Neurobiol Dis 40: 238-244.

Morris AA. 2005. Cerebral ketone body metabolism. J Inherit Metab Dis 28: 109-121.

Mueller SG, Trabesinger AH, Boesiger P, Wieser HG. 2001 Brain glutathione levels in patients with epilepsy measured by in vivo ${ }^{1} \mathrm{H}-\mathrm{MRS}$. Neurology 57: 1422-1427.

Neal EG, Chaffe H, Schwartz RH, Lawson MS, Edwards N, Fitzsimmons G, Whitney A, Cross JH. 2008. The keto- 
M.A. Rogawski et al.

genic diet for the treatment of childhood epilepsy: A randomised controlled trial. Lancet Neurol 7: 500-506.

Neal EG, Chaffe H, Schwartz RH, Lawson MS, Edwards N, Fitzsimmons G, Whitney A, Cross JH. 2009. A randomized trial of classical and medium-chain triglyceride ketogenic diets in the treatment of childhood epilepsy. Epilepsia 50: 1109-1117.

Neuman R, Cherubini E, Ben-Ari Y. 1988. Epileptiform bursts elicited in CA3 hippocampal neurons by a variety of convulsants are not blocked by $N$-methyl-D-aspartate antagonists. Brain Res 459: 265-274.

Oliva M, Berkovic SF, Petrou S. 2012. Sodium channels and the neurobiology of epilepsy. Epilepsia 53: 1849-1859.

Olsen RW, Sieghart W. 2009. GABA A receptors: Subtypes provide diversity of function and pharmacology. Neuropharmacology 56: 141-148.

Otto JF, Kimball MM, Wilcox KS. 2002. Effects of the anticonvulsant retigabine on cultured cortical neurons: Changes in electroresponsive properties and synaptic transmission. Mol Pharmacol 61: 921-927.

Overstreet LS, Westbrook GL. 2001. Paradoxical reduction of synaptic inhibition by vigabatrin. J Neurophysiol 86: 596-603.

Pascual JM, Liu P, Mao D, Kelly DI, Hernandez A, Sheng M, Good LB, Ma Q, Marin-Valencia I, Zhang X, et al. 2014. Triheptanoin for glucose transporter type I deficiency (G1D): Modulation of human ictogenesis, cerebral metabolic rate, and cognitive indices by a food supplement. JAMA Neurol 71: 1255-1265.

Patino GA, Isom LL. 2010. Electrophysiology and beyond: Multiple roles of $\mathrm{Na}^{+}$channel $\beta$ subunits in development and disease. Neurosci Lett 486: 53-59.

Peterman MG. 1924. The ketogenic diet in the treatment of epilepsy: A preliminary report. Am J Dis Child 28: 28-33.

Petroff OAC, Behar KL, Mattson RH, Rothman DL. 1996a. Human brain $\gamma$-aminobutyric acid levels and seizure control following initiation of vigabatrin therapy. $\mathrm{J} \mathrm{Neu}$ rochem 67: 2399-4404.

Petroff OAC, Rothman DL, Behar KL, Lamoureux D, Mattson RH. 1996b. The effect of gabapentin on brain $\gamma$ aminobutyric acid in patients with epilepsy. Ann Neurol 39: 95-99.

Pierre K, Pellerin L. 2005. Monocarboxylate transporters in the central nervous system: Distribution, regulation and function. J Neurochem 94: 1-14.

Porta N, Vallee L, Lecointe C, Bouchaert E, Staels B, Bordet R, Auvin S. 2009. Fenofibrate, a peroxisome proliferatoractivated receptor- $\alpha$ agonist, exerts anticonvulsive properties. Epilepsia 50: 943-948.

Powell KL, Cain SM, Snutch TP, O’Brien TJ. 2014. Low threshold T-type calcium channels as targets for novel epilepsy treatments. Br J Clin Pharmacol 77: 729-739.

Ragsdale DS, McPhee JC, Scheuer T, Catterall WA. 1996. Common molecular determinants of local anesthetic, antiarrhythmic, and anticonvulsant block of voltagegated $\mathrm{Na}^{+}$channels. Proc Natl Acad Sci 93: 9270-9275.

Reddy DS, Rogawski MA. 2002. Stress-induced deoxycorticosterone-derived neurosteroids modulate $\mathrm{GABA}_{\mathrm{A}}$ receptor function and seizure susceptibility. J Neurosci 22: 3795-3805.
Rho JM, Donevan SD, Rogawski MA. 1994. Mechanism of action of the anticonvulsant felbamate: Opposing effects on $N$-methyl-D-aspartate and $\gamma$-aminobutyric acid $_{\mathrm{A}}$ receptors. Ann Neurol 35: 229-234.

Rho JM, Donevan SD, Rogawski MA. 1996. Direct activation of $\mathrm{GABA}_{\mathrm{A}}$ receptors by barbiturates in cultured rat hippocampal neurons. J Physiol 497: 509-522.

Rigoulot MA, Boehrer A, Nehlig A. 2003. Effects of topiramate in two models of genetically determined generalized epilepsy, the GAERS and the Audiogenic Wistar AS. Epilepsia 44: 14-19.

Rogawski MA. 2006. Diverse mechanisms of antiepileptic drugs in the development pipeline. Epilepsy Res 69: 273294.

Rogawski MA. 2013. AMPA receptors as a molecular target in epilepsy therapy. Acta Neurol Scand Suppl 197: 9-18.

Rogawski MA, Cavazos JE. 2015. Mechanisms of action of antiepileptic drugs. In Wyllie's treatment of epilepsy: Principles and practice, 6th ed. (ed. Wyllie E.), pp. 522-529. Wolters Kluwer, Philadelphia.

Rogawski MA, Hanada T. 2013. Preclinical pharmacology of perampanel, a selective non-competitive AMPA receptor antagonist. Acta Neurol Scand 127: 19-24.

Rogawski MA, Porter RJ. 1990. Antiepileptic drugs: Pharmacological mechanisms and clinical efficacy with consideration of promising developmental stage compounds. Pharmacol Rev 42: 223-286.

Rogawski MA, Kurzman PS, Yamaguchi SI, Li H. 2001. Role of AMPA and GluR5 kainate receptors in the development and expression of amygdala kindling in the mouse. Neuropharmacology 40: 28-35.

Rogawski MA, Tofighy A, White HS, Matagne A, Wolff C. 2015. Current understanding of the mechanism of action of the antiepileptic drug lacosamide. Epilepsy Res 110: 189-205.

Rowley S, Patel M. 2013. Mitochondrial involvement and oxidative stress in temporal lobe epilepsy. Free Radic Biol Med 62: 121-131.

Rundfeldt C, Netzer R. 2000. Investigations into the mechanism of action of the new anticonvulsant retigabine. Interaction with GABAergic and glutamatergic neurotransmission and with voltage gated ion channels. Arzneimittelforschung 50: 1063-1070.

Sahara S, Yanagawa Y, O'Leary DD, Stevens CF. 2012. The fraction of cortical GABAergic neurons is constant from near the start of cortical neurogenesis to adulthood. J Neurosci 32: 4755-4761.

Schlanger S, Shinitzky M, Yam D. 2002. Diet enriched with omega-3 fatty acids alleviates convulsion symptoms in epilepsy patients. Epilepsia 43: 103-104.

Schousboe A, Madsen KK, Barker-Haliski ML, White HS. 2014. The GABA synapse as a target for antiepileptic drugs: A historical overview focused on GABA transporters. Neurochem Res 39: 1980-1987.

Shank RP, Maryanoff BE. 2008. Molecular pharmacodynamics, clinical therapeutics, and pharmacokinetics of topiramate. CNS Neurosci Ther 14: 120-142.

Shimazu T, Hirschey MD, Newman J, He W, Shirakawa K, Le Moan N, Grueter CA, Lim H, Saunders LR, Stevens RD, et al. 2013. Suppression of oxidative stress by $\beta$-hydroxy- 
butyrate, an endogenous histone deacetylase inhibitor. Science 339: 211-214.

Silverman RB, Andruszkiewicz R, Nanavati SM, Taylor CP, Vartanian MG. 1991. 3-Alkyl-4-aminobutyric acids: The first class of anticonvulsant agents that activates L-glutamic acid decarboxylase. J Med Chem 34: 2295-2298.

Simeone TA, Wilcox KS, White HS. 2011. Topiramate modulation of $\beta_{1}$ - and $\beta_{3}$-homomeric $\mathrm{GABA}_{\mathrm{A}}$ receptors. Pharmacol Res 64: 44-52.

Sohal VS, Keist R, Rudolph U, Huguenard JR. 2003. Dynamic $\mathrm{GABA}_{\mathrm{A}}$ receptor subtype-specific modulation of the synchrony and duration of thalamic oscillations. J Neurosci 23: 3649-3657.

Stafstrom CE. 2007. Persistent sodium current and its role in epilepsy. Epilepsy Curr 7: 15-22.

Stafstrom CE, Rho JM. 2012. The ketogenic diet as a treatment paradigm for diverse neurological disorders. Front Pharmacol 3: 59 .

Stafstrom CE, Ockuly JC, Murphree L, Valley MT, Roopra A, Sutula TP. 2009. Anticonvulsant and antiepileptic actions of 2-deoxy-D-glucose in epilepsy models. Ann Neurol 65: 435-447.

Stafstrom CE, Arnason BG, Baram TZ, Catania A, Cortez MA, Glauser TA, Pranzatelli MR, Riikonen R, Rogawski MA, Shinnar S, et al. 2011. Treatment of infantile spasms: Emerging insights from clinical and basic science perspectives. J Child Neurol 26: 1411-1421.

Stahl SM, Porreca F, Taylor CP, Cheung R, Thorpe AJ, Clair A. 2013. The diverse therapeutic actions of pregabalin: Is a single mechanism responsible for several pharmacological activities? Trends Pharmacol Sci 34: 332-339.

Steinhoff BJ, Ben-Menachem E, Ryvlin P, Shorvon S, Kramer L, Satlin A, Squillacote D, Yang H, Zhu J, Laurenza A. 2013. Efficacy and safety of adjunctive perampanel for the treatment of refractory partial seizures: A pooled analysis of three phase III studies. Epilepsia 54: 1481-1499.

Stuchlík A, Kubová H, Mares P. 2001. Single systemic dose of vigabatrin induces early proconvulsant and later anticonvulsant effect in rats. Neurosci Lett 312: 37-40.

Sullivan PG, Dube C, Dorenbos K, Steward O, Baram TZ. 2003. Mitochondrial uncoupling protein-2 protects the immature brain from excitotoxic neuronal death. Ann Neurol 53: 711-717.

Sullivan PG, Rippy NA, Dorenbos K, Concepcion RC, Agarwal AK, Rho JM. 2004. The ketogenic diet increases mitochondrial uncoupling protein levels and activity. Ann Neurol 55: 576-580.

Sun GC, Werkman TR, Battefeld A, Clare JJ, Wadman WJ. 2007. Carbamazepine and topiramate modulation of transient and persistent sodium currents studied in HEK293 cells expressing the $\mathrm{Na}_{\mathrm{v}} 1.3 \alpha$-subunit. Epilepsia 48: $774-782$.

Suzuki S, Rogawski MA. 1989. T-type calcium channels mediate the transition between tonic and phasic firing in thalamic neurons. Proc Natl Acad Sci 86: 7228-7232.

Suzuki T, Motohashi H, Yamamoto M. 2013. Toward clinical application of the Keap1-Nrf2 pathway. Trends Pharmacol Sci 34: 340-346.

Sveinbjornsdottir S, Sander JW, Upton D, Thompson PJ, Patsalos PN, Hirt D, Emre M, Lowe D, Duncan JS 1993. The excitatory amino acid antagonist D-CPP-ene
Antiseizure Drugs and the Ketogenic Diet

(SDZ EAA-494) in patients with epilepsy. Epilepsy Res 16: $165-174$.

Taha AY, Ryan MA, Cunnane SC. 2005. Despite transient ketosis, the classic high-fat ketogenic diet induces marked changes in fatty acid metabolism in rats. Metabolism 54: 1127-1132.

Taha AY, Burnham WM, Auvin S. 2010. Polyunsaturated fatty acids and epilepsy. Epilepsia 51: 1348-1358.

Talley EM, Cribbs LL, Lee JH, Daud A, Perez-Reyes E, Bayliss DA. 1999. Differential distribution of three members of a gene family encoding low voltage-activated (T-type) calcium channels. J Neurosci 19: 1895-1911.

Tanner GR, Lutas A, Martinez-Francois JR, Yellen G. 2011. Single $\mathrm{K}_{\text {ATP }}$ channel opening in response to action potential firing in mouse dentate granule neurons. J Neurosci 31: 8689-8696.

Tatulian L, Brown DA. 2003. Effect of the KCNQ potassium channel opener retigabine on single KCNQ2/3 channels expressed in CHO cells. J Physiol 549: 57-63.

Taylor CP, Vartanian MG, Andruszkiewiewicz R, Silverman RB. 1992. 3-Alkyl GABA and 3-alkylglutamic acid analogues: Two new classes of anticonvulsant agents. Epilepsy Res 11: 103-110.

Taylor CP, Angelotti T, Fauman E. 2007. Pharmacology and mechanism of action of pregabalin: The calcium channel $\alpha_{2}-\delta\left(\right.$ alpha $_{2}$-delta) subunit as a target for antiepileptic drug discovery. Epilepsy Res 73: 137-150.

Thio LL, Wong M, Yamada KA. 2000. Ketone bodies do not directly alter excitatory or inhibitory hippocampal synaptic transmission. Neurology 54: 325-331.

Thompson SM, Gähwiler BH. 1992. Effects of the GABA uptake inhibitor tiagabine on inhibitory synaptic potentials in rat hippocampal slice cultures. J Neurophysiol 67: $1698-1701$.

Treven M, Koenig X, Assadpour E, Gantumur E, Meyer C, Hilber K, Boehm S, Kubista H. 2015. The anticonvulsant retigabine is a subtype selective modulator of $\mathrm{GABA}_{\mathrm{A}}$ receptors. Epilepsia 56: 647-657.

Turner JP, Salt TE. 1998. Characterization of sensory and corticothalamic excitatory inputs to rat thalamocortical neurones in vitro. J Physiol 510: 829-843.

Twele F, Bankstahl M, Klein S, Römermann K, Löscher W. 2015. The AMPA receptor antagonist NBQX exerts antiseizure but not antiepileptogenic effects in the intrahippocampal kainate mouse model of mesial temporal lobe epilepsy. Neuropharmacology 95: 234-242.

Tzingounis AV, Heidenreich M, Kharkovets T, Spitzmaul G, Jensen HS, Nicoll RA, Jentsch TJ. 2010. The KCNQ5 potassium channel mediates a component of the afterhyperpolarization current in mouse hippocampus. Proc Natl Acad Sci 107: 10232-10237.

U.S. Food and Drug Administration 2010. Ezogabine for partial seizures in epilepsy (NDA-022345). Peripheral and Central Nervous System Drugs Advisory Committee Briefing Document U.S. Food and Drug Administration, Jersey City, NJ.

Vacher H, Mohapatra DP, Trimmer JS. 2008. Localization and targeting of voltage-dependent ion channels in mammalian central neurons. Physiol Rev 88: 1407-1447.

Vervaeke K, Gu N, Agdestein C, Hu H, Storm JF. 2006. Kv7/ $\mathrm{KCNQ} / \mathrm{M}$-channels in rat glutamatergic hippocampal 
M.A. Rogawski et al.

axons and their role in regulation of excitability and transmitter release. J Physiol 576.1: 235-256.

Vreugdenhil M, Bruehl C, Voskuyl RA, Kang JX, Leaf A, Wadman WJ. 1996. Polyunsaturated fatty acids modulate sodium and calcium currents in CA1 neurons. Proc Natl Acad Sci 93: 12559-12563.

Wakita M, Kotani N, Kogure K, Akaike N. 2014. Inhibition of excitatory synaptic transmission in hippocampal neurons by levetiracetam involves $\mathrm{Zn}^{2+}$-dependent GABA type A receptor-mediated presynaptic modulation. $J$ Pharmacol Exp Ther 348: 246-259.

Waldmeier PC, Baumann PA, Wicki P, Feldtrauer JJ, Stierlin C, Schmutz M. 1995. Similar potency of carbamazepine, oxcarbazepine, and lamotrigine in inhibiting the release of glutamate and other neurotransmitters. Neurology 45: 1907-1913.

Walker MC, Kullmann DM. 2012. Tonic GABA A receptormediated signaling in epilepsy. In Jasper's basic mechanisms of the epilepsies, 4th ed. (Noebels JL, et al., eds.), pp. 111-121. Oxford University Press, New York.

Walker MC, Williams RS. 2013. The search for better epilepsy treatments: From slime mould to coconuts. Biochem Soc Trans 41: 1625-1628.

Weissmann C, Di Guilmi MN, Urbano FJ, Uchitel OD. 2013. Acute effects of pregabalin on the function and cellular distribution of $\mathrm{Ca}_{\mathrm{V}} 2.1$ in HEK293t cells. Brain Res Bull 90: $107-113$.

Wheless JW. 2008. History of the ketogenic diet. Epilepsia 49: $3-5$.

Willis S, Stoll J, Sweetman L, Borges K. 2010. Anticonvulsant effects of a triheptanoin diet in two mouse chronic seizure models. Neurobiol Dis 40: 565-572.
Won YJ, Lu VB, Puhl HL 3rd, Ikeda SR. 2013. $\beta-H y-$ droxybutyrate modulates $\mathrm{N}$-type calcium channels in rat sympathetic neurons by acting as an agonist for the G-protein-coupled receptor FFA3. J Neurosci 33: 19314-19325.

Wu Y, Wang W, Richerson GB. 2003. Vigabatrin induces tonic inhibition via GABA transporter reversal without increasing vesicular GABA release. J Neurophysiol 89: 2021-2034.

Yamaguchi S, Donevan SD, Rogawski MA. 1993. Anticonvulsant activity of AMPA/kainate antagonists: Comparison of GYKI 52466 and NBOX in maximal electroshock and chemoconvulsant seizure models. Epilepsy Res 15: 179-184.

Yu FH, Catterall WA. 2003. Overview of the voltage-gated sodium channel family. Genome Biol 4: 207.

Yudkoff M, Daikhin Y, Nissim I, Horyn O, Lazarow A, Luhovyy B, Wehrli S. 2005. Response of brain amino acid metabolism to ketosis. Neurochem Int 47: 119-128.

Yue C, Yaari Y. 2006. Axo-somatic and apical dendritic $\mathrm{K}_{\mathrm{v}} 7$ / $\mathrm{M}$ channels differentially regulate the intrinsic excitability of adult rat CA1 pyramidal cells. J Neurophysiol 95: 3480-3495.

Yuen AW, Sander JW, Fluegel D, Patsalos PN, Bell GS, Johnson T, Koepp MJ. 2005. Omega-3 fatty acid supplementation in patients with chronic epilepsy: A randomized trial. Epilepsy Behav 7: 253-258.

Zilles K, Qü MS, Köhling R, Speckmann EJ. 1999. Ionotropic glutamate and GABA receptors in human epileptic neocortical tissue: Quantitative in vitro receptor autoradiography. Neuroscience 94: 1051-1061. 


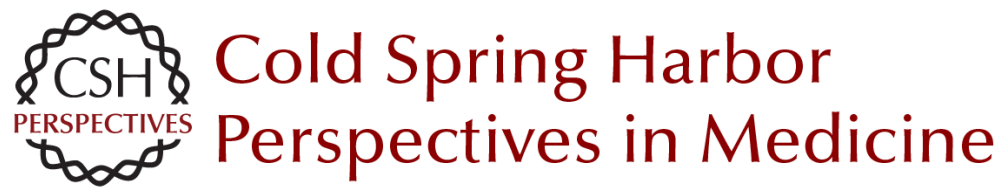

\section{Mechanisms of Action of Antiseizure Drugs and the Ketogenic Diet}

Michael A. Rogawski, Wolfgang Löscher and Jong M. Rho

Cold Spring Harb Perspect Med 2016; doi: 10.1101/cshperspect.a022780 originally published online January 22, 2016

\section{Subject Collection Epilepsy: The Biology of a Spectrum Disorder}

The Epilepsy Spectrum: Targeting Future Research Challenges

Gregory L. Holmes and Jeffrey L. Noebels

Role of Sodium Channels in Epilepsy

David I. Kaplan, Lori L. Isom and Steven Petrou

\section{Mechanisms of Action of Antiseizure Drugs and the Ketogenic Diet \\ Michael A. Rogawski, Wolfgang Löscher and Jong M. Rho}

Epilepsy and Autism

Ashura W. Buckley and Gregory L. Holmes

Immunity and Inflammation in Epilepsy Annamaria Vezzani, Bethan Lang and Eleonora Aronica

Hyperpolarization-Activated Cyclic

Nucleotide-Gated (HCN) Channels in Epilepsy Gary P. Brennan, Tallie Z. Baram and Nicholas P. Poolos

The Role of Calcium Channels in Epilepsy Sanjeev Rajakulendran and Michael G. Hanna

Interneuron Transplantation as a Treatment for Epilepsy

Robert F. Hunt and Scott C. Baraban

\section{Common Mechanisms Underlying Epileptogenesis and the Comorbidities of Epilepsy \\ Andrey Mazarati and Raman Sankar}

The Diathesis-Epilepsy Model: How Past Events Impact the Development of Epilepsy and Comorbidities

Christophe Bernard

Potassium Channels in Epilepsy Rüdiger Köhling and Jakob Wolfart

GABAergic Synchronization in Epilepsy Roustem Khazipov

Status Epilepticus Syndi Seinfeld, Howard P. Goodkin and Shlomo Shinnar

Neonatal and Infantile Epilepsy: Acquired and

Genetic Models Aristea S. Galanopoulou and Solomon L. Moshé

Epigenetics and Epilepsy

David C. Henshall and Katja Kobow

Microcircuits in Epilepsy: Heterogeneity and Hub Cells in Network Synchronization Anh Bui, Hannah K. Kim, Mattia Maroso, et al.

For additional articles in this collection, see http://perspectivesinmedicine.cshlp.org/cgi/collection/ 